\title{
Gradhiva
}

GRADHI

Revue d'anthropologie et d'histoire des arts

$21 \mid 2015$

Création plastique d'Haïti

\section{La peinture naïve haïtienne d'inspiration chrétienne. Discours, héritages, représentations}

Haitian naïve painting of Christian inspiration: discourses, heritages, and representations

Danielle Bégot

\section{(2) OpenEdition}

Journals

Édition électronique

URL : http://journals.openedition.org/gradhiva/2924

DOI : 10.4000/gradhiva.2924

ISSN : 1760-849X

Éditeur

Musée du quai Branly Jacques Chirac

Édition imprimée

Date de publication : 1 février 2015

Pagination : 22-47

ISBN : 978-2-35744-075-3

ISSN : 0764-8928

Référence électronique

Danielle Bégot, «La peinture naïve haïtienne d'inspiration chrétienne. Discours, héritages,

représentations », Gradhiva [En ligne], 21 | 2015, mis en ligne le 01 février 2015, consulté le 23 avril 2019. URL : http://journals.openedition.org/gradhiva/2924 ; DOI : 10.4000/gradhiva.2924

(c) musée du quai Branly 


\section{La peinture naïve haïtienne d'inspiration chrétienne}

Discours, héritages, représentations

par Danielle Bégot

Cet article montre comment, au milieu du $x x^{e}$ siècle et au sein de la peinture naïve haiitienne, à l'origine de la reconnaissance du pays par le marché occidental de l'art, l'expression plastique d'inspiration chrétienne a joué un rôle majeur avant de s'effacer devant les arts du vodou. L'iconographie chrétienne d'Haïti est aujourd'hui mieux connue, constituée à la fois des apports modestes de Saint-Domingue et des images pieuses diffusées aux xIx et $x x^{e}$ siècles par le clergé européen. À l'époque comme aujourd'hui, on retrouve cette puissante imagerie catholique sur les murs des temples vodou. À l'heure actuelle, la peinture naîve d'expression chrétienne se partage entre différents courants: la peinture d'église, réduite à quelques exemples datant des années 1950-1960, la peinture de galerie, achetée par les collectionneurs et par les musées, et les décors des autobus locaux, les tap-tap, qui témoignent de la créativité populaire. Nous mettons ici en évidence les effets, pour la deuxième catégorie, d'un marché de l'art poussant à une fonctionnalité de moins en moins religieuse de la toile et de plus en plus prétexte à une simple rêverie exotique.

mots clés

Haïti, christianisme

haïtien, peinture naïve haïtienne, iconographie chrétienne, vodou. 

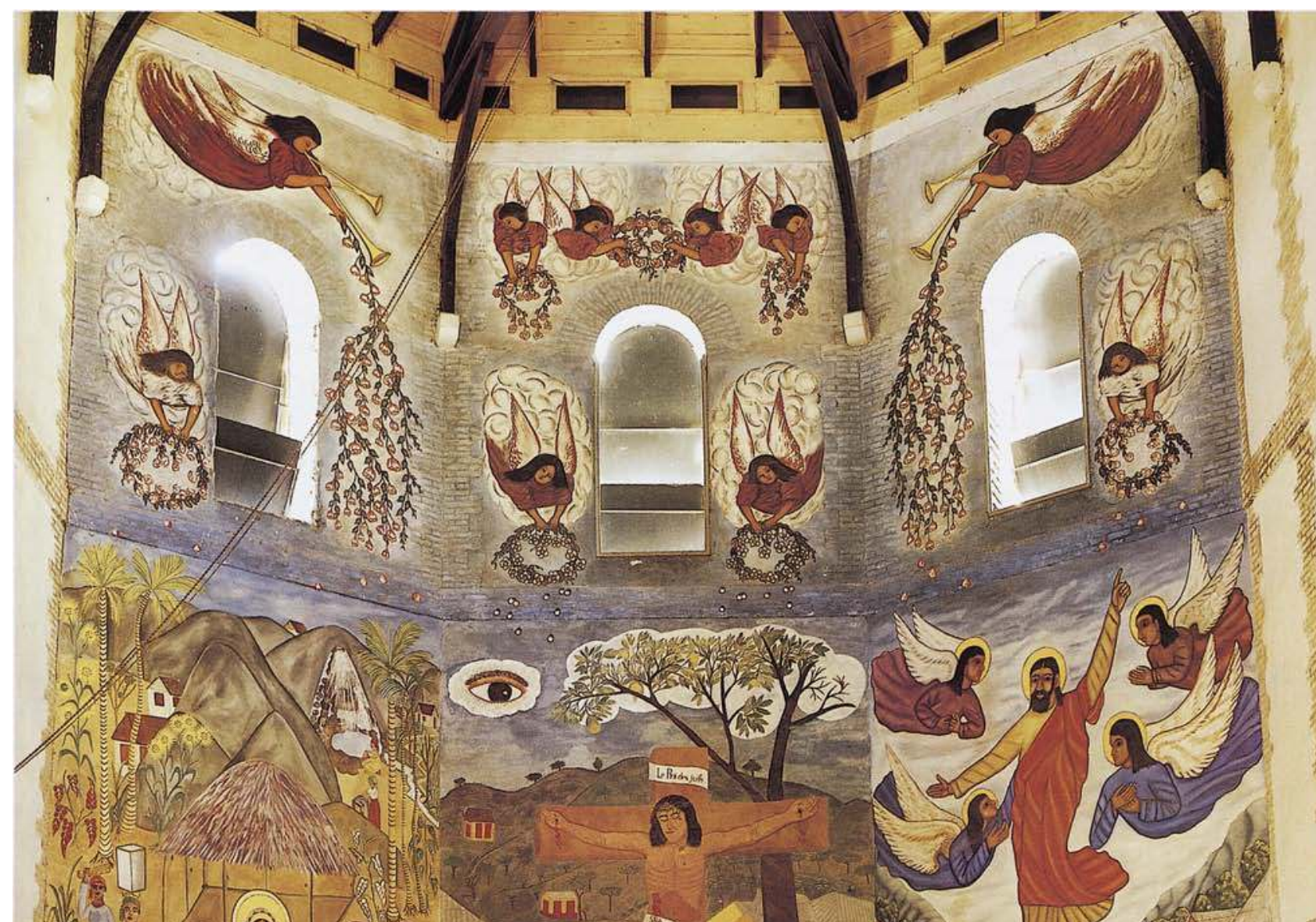

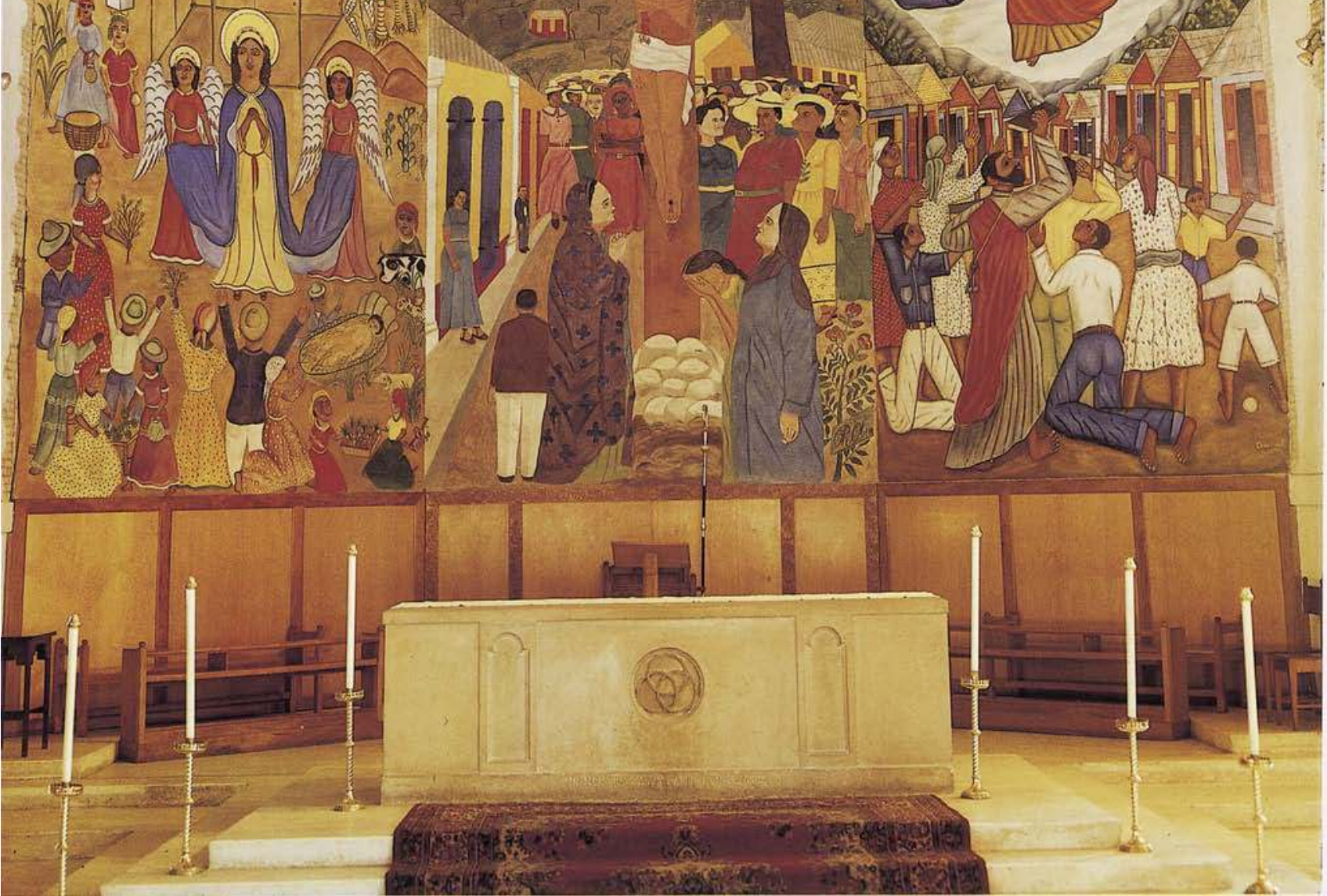




\section{Discours}

De tous les thèmes qu'aborde la peinture haïtienne dite naïve, certains, plus que d'autres, ont attiré la faveur des critiques et du public, hier comme aujourd'hui. Les représentations plastiques inspirées des croyances vodou, cette religion populaire fortement liée à l'histoire d'Haïti qui mêle cultes africains et croyances catholiques, ont bénéficié d'un intérêt jamais démenti depuis la reconnaissance de cette forme d'expression à partir de la création du Centre d'art en 1944. Par comparaison, la peinture d'inspiration chrétienne tient une place nettement plus discrète. Ainsi, dans le Journal de voyage... de Jean-Marie Drot (1974), Peintures haïtiennes des éditions Delroisse (Warren 1978) ou encore Haitian Art, catalogue d'une brillante exposition au Brooklyn Museum à New York (Stebich 1978), ouvrages des années 1970 encore considérés comme des références, la faible part accordée àl'iconographie chrétienne frappele lecteur. Paradoxalement, Drot, qui présente son livre comme une invitation au voyage chez «les peintres de la fête et du vodou », est celui des trois qui lui réserve le plus de place $(12,5 \%$ des illustrations). Chez Delroisse, celle-ci se réduit à 6,2\%, à peu de choses près le pourcentage atteint par le catalogue du Brooklyn Museum (7\%). La donne ne change pas vraiment durant la décennie suivante, la dernière avant que les troubles politiques affectent sérieusement le marché de l'art haïtien. Sans doute Selden Rodman, qui a encadré la réalisation des décors muraux de la cathédrale épiscopalienne de la Sainte-Trinité à Port-auPrince, consacre-t-il $15 \%$ des reproductions de son Where Art is Joy (1988) aux œuvres d'inspiration chrétienne, mais la même année, à Paris cette fois, l'exposition du Grand Palais conçue par Drot et Gérald Alexis, alors directeur du musée du Panthéon national d'Haïti, se place sous le diptyque Haïti: art naïf, art vodou, et son catalogue n'accorde guère plus du dixième de ses illustrations (11\%) aux thèmes chrétiens. En 1986, la proportion chute plus bas encore, à $3 \%$, chez Marie-José Nadal-Gardère et Gérald Bloncourt, deux artistes haïtiens qui publient aux éditions Nathan Peinture haïtienne (Nadal-Gardère et Bloncourt 1986). Conclusion provisoire qui paraît confirmer cette tendance de fond: l'exposition Les musées sont des mondes, tenue au Louvre en 2011 (Le Clézio 2011: 149-154), n'intègre aux œuvres haïtiennes aucun tableau qui renverrait au symbolisme chrétien.

Cet état de fait peut surprendre. On sait le rôle qu'ont joué les fresques de la cathédrale de la Sainte-Trinité, autour des années 1950, dans la reconnaissance du courant «primitif», au moins auprès du public américain car l'indifférence des critiques français ${ }^{\mathbf{1}}$, durement épinglée par Rodman (1988: 110), a mis plusieurs décennies à s'effacer ${ }^{2}$. On sait également l'extraordinaire réservoir que constituent, pour l'imagerie religieuse, ces décors de tap-tap qui transforment une partie des autobus locaux en ex-voto pour le Dieu chrétien et ses saints (l'orthodoxie de certaines de ces représentations est un tout autre problème). On sait, enfin, que quelquesuns des plus beaux tableaux de la collection permanente du musée d'Art haïtien du collège Saint-Pierre, à Port-au-Prince, telle qu'elle existait avant le désastre du tremblement de terre de 2010, sont sans aucune équivoque des œuvres d'expression chrétienne.

II n'en reste pas moins que la «peinture populaire haïtienne», pour reprendre le titre d'un article de Lisa Bastien paru en 1954, dix ans après
1. Le Guide bleu AntillesGuyane (Hachette), rédigé par les Martiniquais Maurice et Jacqueline Clerc, signale tout de même dès 1963 qu'à Port-au-Prince on peut « admirer des œuvres d'art de l'art contemporain, dans plusieurs églises, à l'aéroport et dans plusieurs boutiques" (p. 439).

2. L'évolution est manifeste entre Drot première manière, de 1974, qui ignore totalement les peintures de la Sainte-Trinité, et le catalogue de 1988 qui leur consacre plusieurs illustrations.

page ci-contre

fig. 1

Fresques murales de la cathédrale de la Sainte Trinité, Port-au-Prince. De gauche à droite, fresques de Rigaud Benoit, Philomé Obin et Castera Bazile, in Jean-Marie Drot, Voyage au pays des naïs, 1986, Hatier, p. 166. D.R. 
3. Ce qui ne signifie évidemment pas que les Haïtiens ne s'intéressent pas à leur expression artistique, leurs travaux sont là pour démontrer le contraire. Mais les lois du marché, à la fois pour la vente des tableaux et celle des ouvrages, font que la clientèle visée est d'abord une clientèle étrangère.

4. Paroles relevées dans Connaissance des arts, $n^{\circ} 379$, septembre 1983 , p. 26.

5. "Habitation" est à prendre ici dans son sens historique de "plantation " aux Antilles de colonisation française. l'ouverture du Centre d'art, ne s'est pas fait connaître en empruntant immédiatement cette voie, pas plus à la première exposition du Centre d'art à Port-au-Prince (1944) qu'à l'Exposition internationale d'art moderne de Paris organisée par l'Unesco en 1946. L'étude de Lisa Bastien (1954: 215-232) l'illustre parfaitement: si, à côté d'Hector Hippolyte, figurent Rigaud Benoit, Louverture Poisson et Préfète Duffaut, les œuvres d'inspiration chrétienne sont passées sous silence. II faut bien constater qu'une fois passé l'émerveillement initial pour les peintures murales des Wilson Bigaud, Philomé Obin, Castera Bazile, etc., de la cathédrale Sainte-Trinité, l'intérêt du public et des collectionneurs (massivement occidentaux, il convient de le rappeler ${ }^{3}$ ) s'est tourné vers d'autres horizons, comme en témoignent les ouvrages cités. Certes, l'arbitraire peut toujours présider à la sélection des illustrations retenues par les maisons d'édition (quelle part revient à l'auteur? à l'éditeur?), et cette sélection pourrait majorer l'ampleur de la désaffection réelle. Pour autant, il paraît difficile de nier ce que ce choix révèle des goûts et des désintérêts du plus grand nombre.

Plusieurs handicaps pèsent en effet sur cette thématique. Celle-ci naît d'abord d'une inspiration qui a cessé de séduire, trop éloignée des préoccupations quotidiennes d'un Occident toujours plus laïcisé, et qui ne crève les plafonds du marché de l'art chez Sotheby's ou Christie's qu'en vertu de la signature du maître et non de la valeur du symbole. Mais il faut aussi tenir compte, dans la peinture haïtienne contemporaine, du statut un peu bâtard des œuvres qui s'y rattachent: non seulement ces représentations de la Nativité ou de la Crucifixion ne peuvent fonctionner comme des œuvres «primitives" (leur nature les en rend bien incapables), mais elles représentent de plus, pour beaucoup d'étrangers, un produit hybride, trop lié à l'Europe pour être «primitif», «exotique», et trop éloigné d'elle par la présence d'éléments «typiques» pour être récupéré tel quel. Ajoutons aux explications la remarque d'un expert qui concluait ainsi une médiocre vente aux enchères de statuaire africaine à Paris: «Un objet, si beau soit-il, perd infiniment de son prestige si sa participation à des cérémonies rituelles ne peut être assurée ${ }^{4}$. " Or les œuvres picturales d'inspiration chrétienne ne répondent qu'occasionnellement, et non pas systématiquement, à une justification de type fonctionnel.

Il est difficile, ensuite, de ne pas tenir compte à leur propos du changement radical de contexte dans lequel s'inscrit le christianisme colonial et postcolonial, enraciné dans une tradition étrangère qui, même nationalisée, porte toujours la marque d'une histoire trouble (le christianisme vu comme un agent de colonisation et la source d'une justification de l'esclavage dans le Nouveau Monde). En tant qu'objet historique, il a été dans l'Amérique des plantations une religion imposée, arrivée dans le sillage de la colonisation européenne et du maître blanc. Le badigeonnage hâtif d'un vernis de catholicisme sur les «Nègres nouveaux» brutalement transplantés d'Afrique (Cabon 1933: 27) et l'existence sur les habitations coloniales ${ }^{5}$ d'une "vie religieuse sous contrainte» (Delisle 2006: 53) ont repoussé dans la clandestinité des croyances africaines déjà mises à mal par le système de la plantation et qui n'ont dû leur salut, à Haïti, qu'à l'indépendance.

L'essor du vodou après 1804 n'empêche cependant pas l'existence du fait catholique à Haïti. La plupart des chefs historiques de la Révolution 
accordent au christianisme une place particulière dans le nouvel État: la Constitution de 1801 de Toussaint Louverture proclame que «la religion catholique, apostolique et romaine est la seule publiquement professée dans la colonie" (Cabon 1933: 79) et, en 1807, l'acte constitutionnel promulgué par Henri Christophe (Moïse [dir.] 2003: 78) reconnaît comme seule religion la religion catholique. Le concordat de 1860, qui intervient après une rupture de plus d'un demi-siècle des liens avec le Saint-Siège, la proclame religion de la "grande majorité des Haïtiens", "spécialement protégée"; celui de 1966 confirme $^{6}$. En dépit de ses disputes avec le monde politique, notamment à propos de la constitution d'un clergé national pour lutter contre le monopole français sur l'encadrement catholique (Delisle 2003: 25 et 142), puis concernant la question de l'implantation des Églises protestantes, l'Église catholique devient, en 1966, «l'appareil le plus puissant de l'État haïtien" (Hurbon 1987: 110). Quant au vodou, même si certains représentants suprêmes du pays s'en sont ouvertement réclamés (ainsi de Faustin Soulouque, empereur de 1849 à 1859, et de François Duvalier, président de 1957 à 1971), sa perception reste très longtemps celle que bâtissent État, Église et bourgeoisie, dont l'alliance sur ce sujet ne connaît que peu de relâchement.

Dénoncé comme un amalgame de « fétichisme, sorcellerie et pratiques superstitieuses", pour reprendre le jugement, banalement exemplaire, d'un missionnaire breton envoyé à Haïti dans les premières décennies du xxe siècle (Bonnaud 1938: 199), le vodou se trouve confronté à de violentes contre-attaques de l'Église. II est bon de garder en mémoire que l'une de ces "campagnes anti-superstitieuses", dont Alfred Métraux a noté les effets destructeurs lors de son premier séjour haïtien, en 1941 (Métraux 1958: 12-13), se situe seulement quelques années avant l'exécution des fresques de la Sainte-Trinité, menée entre 1949 et 1951. Parallèlement, le retour sur soi entamé par le mouvement indigéniste et institutionnalisé par le Bureau d'ethnologie fondé par Jacques Roumain, en 1941 justement (Célius 2005), ainsi que l'arrivée, sous l'occupation étatsunienne, de chercheurs américains élevant le vodou au rang de religion populaire digne de respect ( $R$. Bastien 1966: 40) et non plus de mascarade, rebattent les cartes. Aux classes populaires, dans lesquelles vodou et catholicisme s'interpénètrent, le catholicisme finit par apparaître comme la religion des élites, détournée d'une authentique culture nationale (Hurbon 1972: 13).

Plus séduisante pour une certaine intelligentsia européenne qui y étanche, après la Seconde Guerre mondiale et avec André Breton, sa vieille soif d'un monde nouveau, plus rassérénante pour les Américains puisque, par ses connotations de pratiques magico-religieuses, elle justifie a posteriori leur occupation du pays entre 1915 et 1934, labellisée «authentique» par le marché de l'art, la production artistique liée au vodou a par comparaison tout pour plaire. D'autant que d'authentiques chefs-d'œuvre y fleurissent dans les années entourant la naissance du Centre d'art, même si celui-ci ne s'est pas constitué en fonction d'une peinture naïve alors inconnue ni d'une peinture vodou encore à découvrir (Lerebours 1989: 245). Si, en 1950, l'Américain Rodman peut convier les lecteurs de Harper's Bazaar à découvrir l'image du Christ chez les primitifs haïtiens (Rodman 1950 ) et si deux ans plus tard, à la radio jamaïcaine (Nadal-Gardère et
6. Le texte est accessible sur www.haiti-reference. com/religion/.../ concordats/.php. 
7. Ounfò : bâtiment dédié au culte vodou.

8. Guadeloupe, collection particulière.

9. Georges Remponeau, "You témouin 1944 ap palé " ("Un témoin de 1944 parle»). Sauf indication contraire, les traductions du créole haïtien sont de Danielle Bégot.
Bloncourt 1986), Dewitt Peters peut juger que les fresques de la SainteTrinité constituent «le point culminant des peintres populaires haïtiens en tant que groupe» et le Paradis terrestre de Bigaud «le chef-d'œuvre de la réalisation personnelle d'un artiste haïtien » (fig. 2), le Français Drot préfère donc, un quart de siècle plus tard, afficher dès son titre l'équivalence entre peinture haïtienne et peinture vodou. L'exposition du Brooklyn Museum, en 1978, ne le formule pas de la même manière, mais il n'en reste pas moins que ce sont des œuvres d'inspiration vodou qui servent de couverture à son catalogue. On y perçoit par ailleurs, grâce à certains choix affichés, à quel point le monde du vodou englobe le reste dans l'esprit de ses organisateurs: ainsi le petit Portement de croix de Bigaud figure-t-il dans le chapitre "Voodoo and art» (Stebich 1978: 63) alors que rien dans son traitement ne permet un pareil glissement d'interprétation (le commentaire, d'ailleurs, en fait foi). Tout aussi gênant, mais ce phénomène vaut de manière générale: l'attribution des œuvres s'opère dans un sens beaucoup plus restrictif pour la peinture "chrétienne» que pour l'autre famille. Une représentation d'ounfò ${ }^{7}$ avec des fidèles y est automatiquement étiquetée "scène vodou " alors qu'une chapelle, une église, une cérémonie catholiques se trouvent dans le même cas de figure renvoyées à "paysage" ou "scène de la vie quotidienne", jamais à "scène de la vie chrétienne ", tout simplement parce que cette catégorie thématique n'existe pas. Mais n'est-ce pas amputer d'une partie de son sens le Boulé Bois Saint-Jean, Trou du Nord, d'Étienne Chavannes $^{8}$ (vers 1980 , fig. 3), où une foule mi-urbaine mi-paysanne se presse pour voir défiler le curé et ses enfants de chœur qui vont mettre le feu au bûcher de la Saint-Jean, que de le réduire à une scène de la vie de tous les jours?

C'est tout à la fois l'inconstance d'un certain regard occidental et ses excès simplificateurs qu'ont voulu dénoncer des chercheurs haïtiens, récusant aussi bien le rôle fondateur des peintures de la Sainte-Trinité que l'authenticité d'une production vodou exubérante. Pour citer ce que l'historien d'art Michel-Philippe Lerebours écrivait au début des années 1980 (Lerebours 1981: 54):

Tout dans la peinture haïtienne n'est pas expression des croyances vodou [...]. De nombreux artistes haïtiens ne sont point vodouisants pratiquants et n'ont aucune connaissance réelle du vodou. S'il leur est arrivé d'en parler, c'est d'une façon toute superficielle et seulement pour répondre aux exigences du marché. D'autres, comme les Obin ou Jasmin Joseph, se défendent d'être vodouisants et se sont même interdit d'en parler.

Ils sont également chrétiens et n'ont éprouvé aucune gêne à parler de leur religion et à leur façon. La peinture haïtienne n'a pas attendu 1950 et les peintures murales de la Sainte-Trinité pour s'inspirer des thèmes chrétiens et les haïtianiser.

Peu importent, ici, les raisons profondes à l'origine de cette prise de position. Rejet nationaliste du patronage de Peters, à la fois salué (Nadal-Gardère et Bloncourt 1986: 40) et discuté (Sè/9 1977: 6; Lerebours 1989), mouvement d'humeur contre les réductions simplificatrices où communient trop volontiers prospectus touristiques et certains ouvrages d'art, 


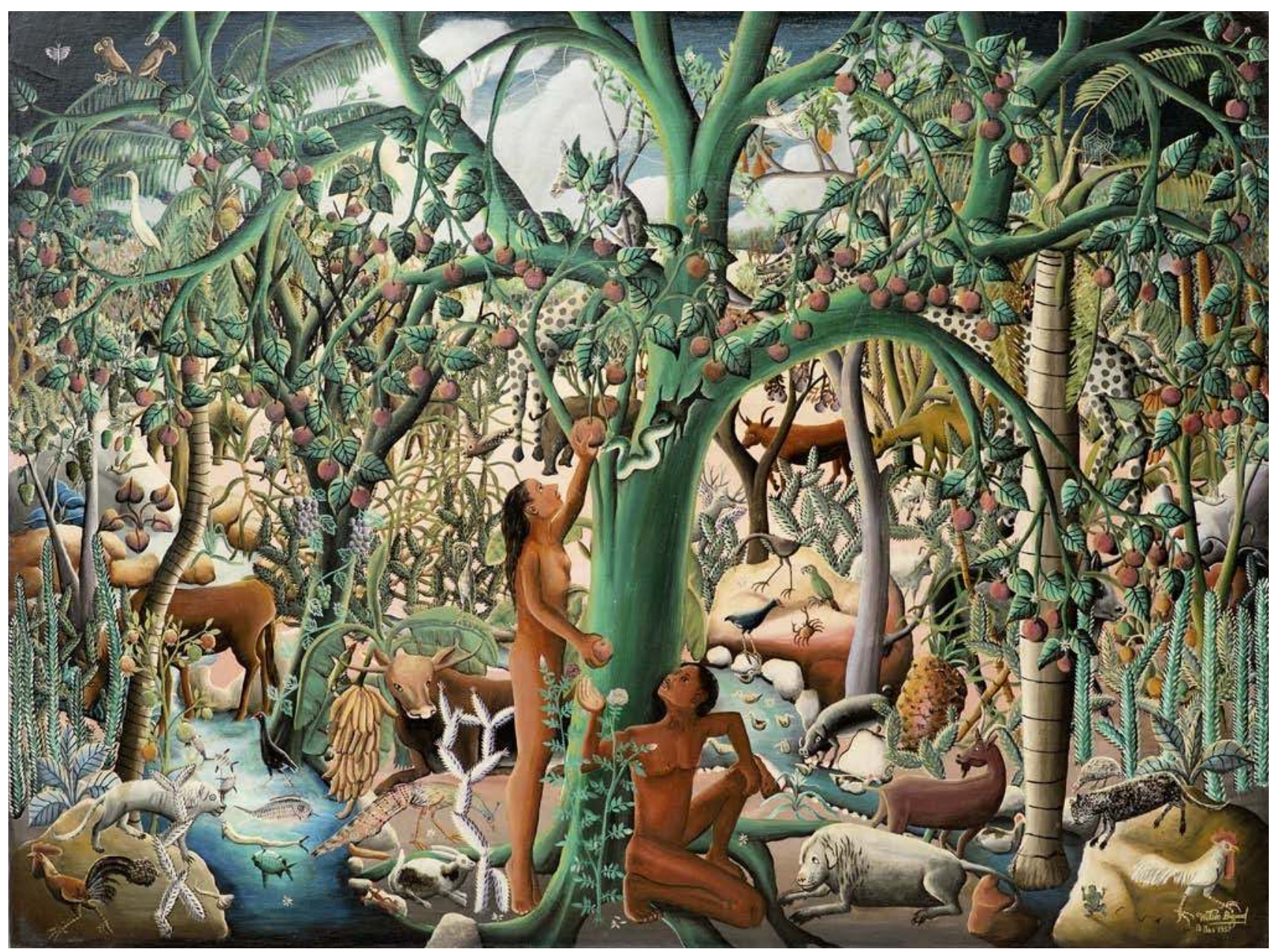

fig. 2

Wilson Bigaud, Paradis

Terrestre, 1952, huile sur isorel. Musée d'Art haïtien

du collège Saint-Pierre.

Don du Centre d'Art.

(c) Photo Dominique Franck

Simon / Photo Pro Studio. 
10. The original who paints "what he sees" and creates new forms out of nothing is a Romantic myth. Even the greatest artist - and he more than others needs an idiom to work in Only tradition, such as he finds it, can provide him with the raw material of imagery which he needs. (Traduction de la rédaction de Gradhiva) ou recherches historiques de fond sur la peinture haïtienne antérieure à 1944 (Hoffmann 1981; Lerebours 1981)? On se montrera plus sensible aux implications que cette logique entraîne, dont la moindre n'est pas de revendiquer comme authentiquement nationale la peinture chrétienne des tout débuts de l'État haïtien plutôt que - en caricaturant l'argumentation de Lerebours - les œuvres d'Hyppolite ou d'André Pierre. Paradoxale et volontiers provocante quand on songe à la revalorisation du vodou dans la culture haïtienne contemporaine, cette conclusion a le mérite de réintroduire l'art chrétien dans la création plastique nationale. Plus encore, elle nous oblige à nous interroger sur ses racines historiques car, s'il est un domaine où la tradition visuelle joue un rôle capital, c'est bien dans l'élaboration et la transmission de ce type d'iconographie. Comment ne pas songer à ce propos à l'élégante mais ferme mise au point d'Ernst Gombrich, curieusement contemporaine, à trois ans près, de la création du Centre d'art de Port-au-Prince (Gombrich 1978 [1963] : 126):

L'excentrique qui peint "ce qu'il voit» et crée ainsi de nouvelles formes à partir de rien est un mythe romantique. Même le plus grand artiste, et surtout lui, a besoin du cadre d'un langage. Seule la tradition, telle qu'il la découvre, peut lui fournir la matière brute, les images nécessaires ${ }^{10}$.

\section{Généalogies: la transmission de l'iconographie chrétienne}

La transmission de l'iconographie chrétienne est complexe car elle couvre une très longue période: un siècle et demi entre la fin de SaintDomingue et les fresques de la Sainte-Trinité, deux et demi si l'on englobe la période coloniale. L'iconographie chrétienne, de surcroît, a toujours été présente, quelle qu'ait été la situation de l'Église à Haïti, et la première raison en est, comme le rappelait le chanoine Delaruelle, que les images ne sont pas pour l'Église «un moyen occasionnel, elles sont l'expression normale et comme organique des mystères chrétiens » (Le Goff 1968: 47).

Qu'à Saint-Domingue les lieux de culte n'aient péché ni par luxe ostentatoire ni par grande recherche du côté du décor, une source historique comme la Description de la partie française de l'isle de Saint-Domingue de Médéric Louis Élie Moreau de Saint-Méry en témoigne à l'évidence (Célius 2001: 434-435; Bégot 2006). Dans les sanctuaires qu'il visite à la fin du $\mathrm{XVIII}^{\mathrm{e}}$ siècle, dont il donne parfois l'état ancien, l'absence de tableaux est la norme. Seuls quatre d'entre eux en possèdent ou en ont possédé un, unique; l'exception est la dernière église du Cap, érigée en 1774, qui en compte cinq. Ce maigre bilan est de plus réduit à néant, ou presque, par les destructions causées par la guerre contre les Français. De brèves descriptions permettent toutefois de se faire une idée de ce que représentaient ces œuvres, exécutées par des artistes de France ou parfois des natifs de l'île, comme dans l'église paroissiale de la Croix-des-Bouquets décorée vers 1766 par le mulâtre libre Michel, que l'auteur de la Description... ne cite pas. Cette église n'existe d'ailleurs plus à son passage (Fouchard 1988a [1953]: 59 [Affiches américaines..., 4 mars 1767]; Moreau de Saint-Méry (1984 [1796-1797]), vol. II: 957). Par rapport à la peinture d'inspiration chrétienne postérieure à 1944, un thème semble s'imposer, celui du saint patron de l'église ou du donateur: à l'Arcahaie, saint Pierre; à Sainte-Suzanne, 
la sainte protectrice; au Cap, à Notre-Dame, un saint François, un saint Bonaventure et un saint Saintin (Moreau de Saint-Méry 1984 [1796-1797], vol. I: 336-337). Viennent ensuite, toujours dans cette église, une Assomption, en fait une sculpture, et une Adoration des mages (ibid.). Les précieux dépouillements opérés par Jean Fouchard dans le journal Affiches américaines de Saint-Domingue permettent d'ajouter à ces peintures quelques tableaux possédés par des particuliers, dont deux épisodes de l'Ancien Testament: Josué arrêtant le soleil et un passage de la mer Rouge, propriété d'un négociant du Cap dans les années 1760 (Fouchard 1988b [1955] : 43).

CEuvres de médiocre qualité peut-être, ce dont Moreau de Saint-Méry ne fait pas mystère pour ce qu'il a pu voir, mais malgré tout essentielles: si la période coloniale n'a pas favorisé l'émergence d'un art sacré, elle a néanmoins fourni un code culturel et des références iconographiques. On comprend ainsi qu'ait pu fleurir dans le nouvel État indépendant toute une peinture chrétienne qui bénéficiait chez ses commanditaires et ses exécutants d'une familiarité de l'œil et de l'esprit perpétuée bien au-delà de la rupture politique de 1804. L'intervention des chefs de l'État (qui sont aussi chefs de l'Église jusqu'en 1860) et de leurs proches dans l'embellissement des lieux du culte s'inscrit dans la logique de cette politique. Ainsi naquirent le Christ de Christophe à l'église de Milot au lendemain de l'indépendance, celui de Faustin Soulouque au milieu du siècle (Hoffmann 1981: 55) et diverses représentations de saints (Lerebours 1989: 132). Que les deux Christ aient été représentés avec une peau noire signifie certes l'appropriation des valeurs des anciens maîtres et leur retournement symbolique, mais ils affichent tout autant la volonté de maintenir le lien avec le christianisme perçu comme une des affirmations du pouvoir.

Cette peinture d'église du XIX $x^{e}$ siècle a presque complètement disparu, mais les traces pistées par Lerebours et Léon-François Hoffmann ont montré qu'elle a inspiré les artistes locaux, en particulier sous Soulouque. Les saints patrons du sanctuaire ou du donateur ont continué d'afficher leur popularité, saint Jacques et saint Faustin par exemple (ibid. : 131-132), de même que le Christ, mais tous sont éclipsés par la représentation de la Vierge, qui à elle seule représenterait la moitié des tableaux retrouvés par Hoffmann (1981: 50-55) dans des témoignages de voyageurs.

Pour autant, dans la diffusion de l'iconographie chrétienne, la peinture d'église est loin d'avoir agi seule. Toute une imprégnation s'est opérée par le biais des images pieuses antérieures aux chromolithographies de la fin du $x I x^{e}$ ou $d u x x^{e}$ siècle. La catéchèse post-tridentine, dans laquelle vit la France $d u x \|^{e}$ siècle, en use comme fers de lance du message chrétien; à SaintDomingue, une part non négligeable de l'apostolat des jésuites auprès des esclaves repose sur elles. Du moins c'est ce que l'on déduit de la démonstration établie par Charles Frostin de la cohérence et de l'identité des mécanismes missionnaires des jésuites en terre américaine (Frostin 1979). L'image y est partout présente, sollicitée sous toutes ses formes dès la fin du XVII siècle par les missionnaires qui distribuent «médailles, chapelets et images de toute sorte». Le père Mongin à Saint-Christophe (Chatillon 1984: 117) ou le père Jean de La Mousse en Guyane produisent ainsi devant leurs ouailles, ici des Indiens, images, peintures et estampes (Bianchi 1984: 60 et 76). double page suivante

fig. 3

Étienne Chavannes, Boulé Bois Saint-Jean, Trou du

Nord, vers 1980. Collection particulière, Gouadeloupe. 


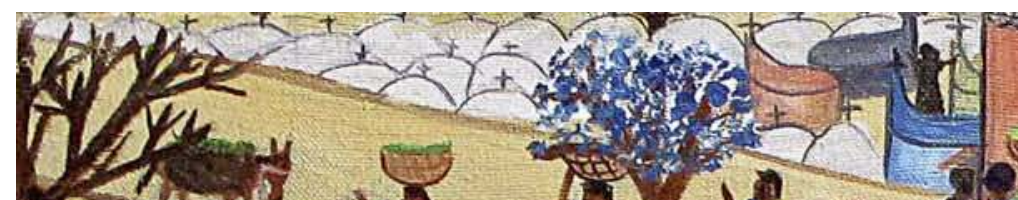

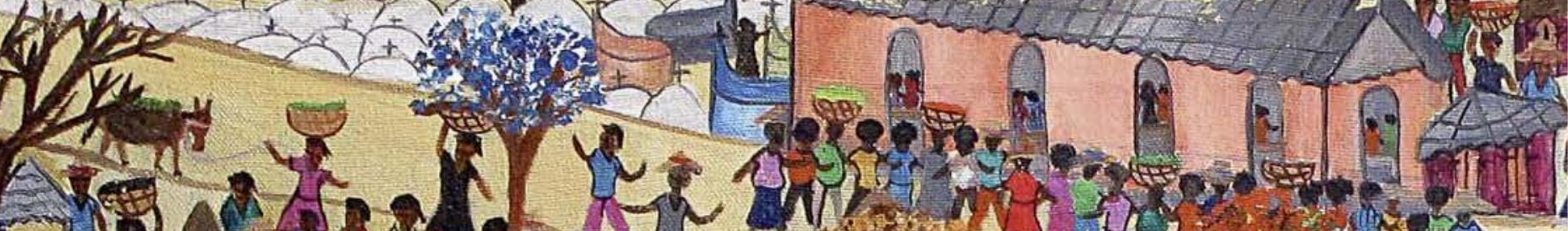
Fin (a)

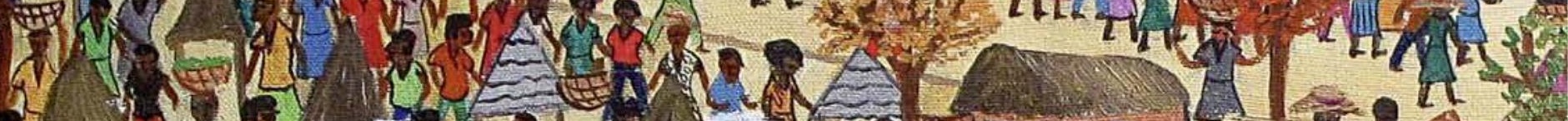

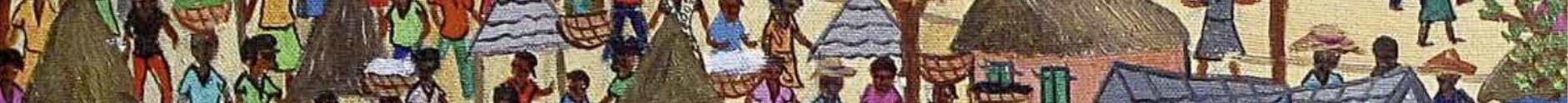

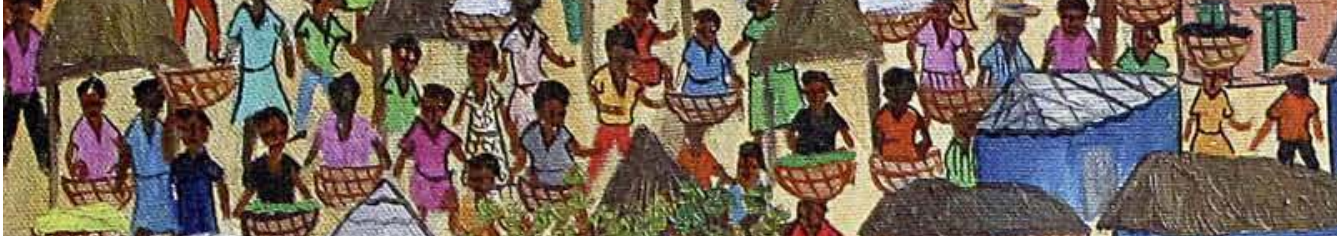

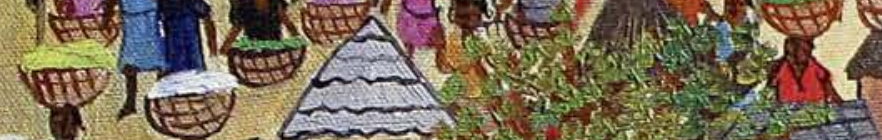
W. y.t.

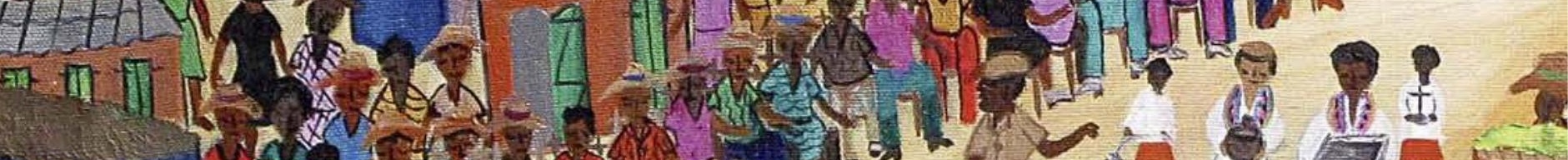
Wa

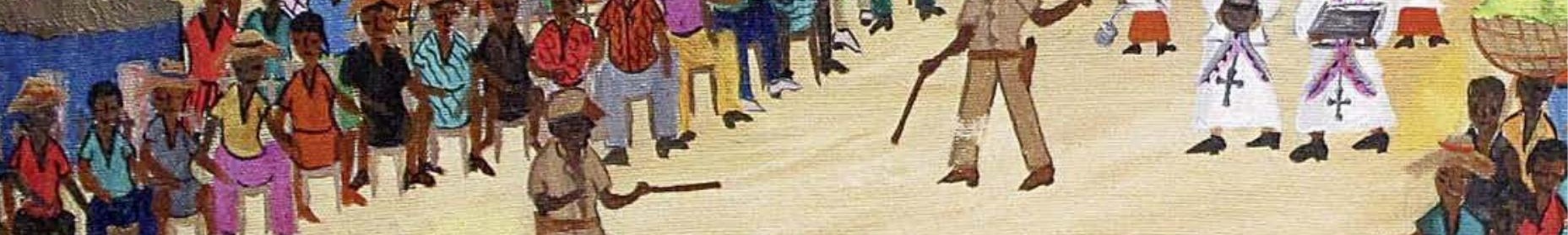
Allk:

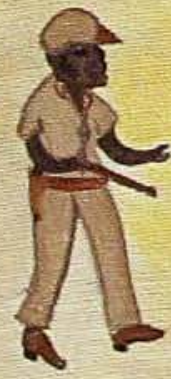

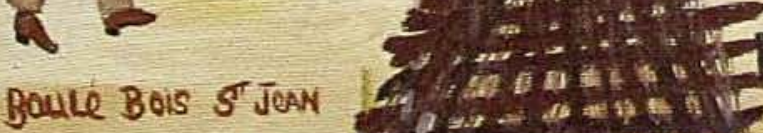

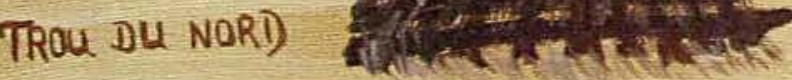
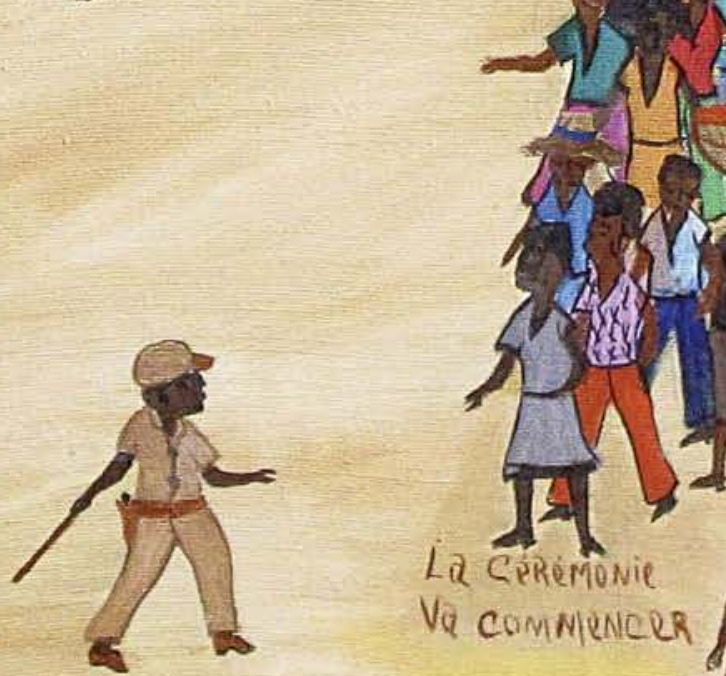
II serait tentant d'opposer les peintures d'église à ces petites images que l'on se représente volontiers grossières, exhibées par le clergé à ses ouailles de couleur. Mais cette idée de deux circuits parallèles d'imageries religieuses distinctes ne tient pas à la lumière des faits. Mongin catéchise à travers champs à l'aide d'un «petit et excellent tableau d'une âme damnée », commentant: «Je n'ai vu en ma vie rien de plus affreux en ce genre » (Chatillon 1984: 113); quant à Jean de La Mousse, il parle bien d'«estampes», mais tout autant de peintures. Inversement, à Saint-Domingue, la première église du Quartier-Morin ne présentait en 1668 pour tout décor que «deux vieilles statues [de] deux anges » et «huit petites images de papier » (Moreau de Saint-Méry 1984 [1796-1797], vol. I: 238). L'interpénétration des deux modes d'expression est donc une constante et le passage de l'un à l'autre facilité, on peut le penser, par la simplicité de la facture et le symbolisme appuyé du message.

À ces missions sur le terrain il convient d'ajouter pour les esclaves les messes basses du dimanche, dites «messes des Nègres", que mentionne Moreau de Saint-Méry (ibid. : 338) mais qui, à la fin du xVIII ${ }^{\mathrm{e}}$ siècle, ne semblent plus beaucoup concerner les esclaves de plantation (Debien 1974: 272-273). Par ces passages à l'église paroissiale, même s'ils ne concernent que les esclaves urbains et les libres de couleur, a pu s'établir un contact, sinon approfondi du moins répété, avec la représentation des scènes sacrées, sans oublier que la lecture de l'image reste fondamentalement liée à la compréhension préalable de l'histoire racontée (Gombrich 1983 [1972]: 345). Les problèmes de diglossie de la colonie entre français et créole, les esclaves ne parlant quasiment que cette lingua franca, n'arrangent rien. L'efficacité du procédé n'est pas niable pourtant, augmentée dans bien des cas par la puissante attraction d'un objet destiné à rester unique et sans rival, en particulier dans le cas d'un tableau. Témoin, I'histoire de la “Négresse albinos», Marguerite Rebecca, rapportée par Moreau de SaintMéry: fille légitime d'une mère dévote, sans doute libre de couleur, elle aurait, pour l'avoir trop fixé durant sa grossesse, transmis à son enfant le teint du personnage féminin du tableau du maître-autel, une reine offrant un ex-voto - le vœu d'Anne d'Autriche? (Moreau de Saint-Méry 1984 [17961797], vol. I: 74-75, citant les Affiches américaines du 23 décembre 1767).

Dans le $x x^{e}$ siècle haïtien, le recours à l'image de dévotion se trouve confirmé à intervalles réguliers. En 1819, on peut supposer qu'un saint Antoine figure dans le petit oratoire privé dédié à ce saint par une dévote de Port-au-Prince qui, par ses bougies, aurait mis le feu au quartier (Milscent 1820: 65). En 1840, lors des cérémonies de la réédification de l'église paroissiale de Notre-Dame, au Cap, le clergé défile «précédé des bannières, des images, des statues des saintes et des saints qui décorent l'église», comme nous le rapporte une petite brochure du temps (Cliquot 1840: 18), perpétuant le rôle de la procession édificatrice déterminé par le concile de Trente. À peu près à la même époque, un autre type de procession est décrit par Victor Schoelcher, qui séjourne au Cap lors des fêtes de Pâques: le Vendredi saint, de toutes petites filles portent les instruments de la Passion en carton colorié, «l'éponge, le suaire, les dés, l'échelle, les clous, le marteau, les tenailles» (Schoelcher 1843: 292), figuration que certaines images de piété françaises de la seconde moitié du XIX ${ }^{e}$ siècle reprennent, montrant la croix flanquée de 
ces mêmes accessoires (Rosebaum-Dondaine 1984: 154). Près d'un siècle plus tard, à la Fête-Dieu célébrée dans les rues de Port-au-Prince, les reposoirs érigés devant les maisons mêlent plantes vertes, «statuettes et images pieuses $11 »$ (Mayard s.d. [1967]: 129).

Le concordat de 1860 a donné un nouvel essor à l'image pieuse. Philippe Delisle (2003: 40) décrit l'apostolat des pères montfortains, très actifs dans les années 1870, qui distribuent médailles et images dans les coins les plus reculés de leurs paroisses. Que ce soit par ces réseaux missionnaires ou par l'effet d'un petit colportage, ce type d'objet de dévotion se répand largement. Le Français Eugène Aubin, un bon observateur du pays, note au début $d u x x^{e}$ siècle la présence courante d'objets de piété (des images?) aux murs des très modestes foyers qui occupent les hauteurs de Furcy, dans la région de Port-au-Prince (Austin 1910: 124). À la veille de la Seconde Guerre mondiale, le père Bonnaud, chargé de la nouvelle paroisse de La Vallée, près de Jacmel, confirme: si, sur ses 32000 paroissiens, à peine 3000 sont pratiquants, les autres possèdent généralement, dans un coin de la maison, au moins un «modeste oratoire orné d'images de saints protecteurs» (Bonnaud 1938: 37 et 183). Iconographie chrétienne, certes, mais faut-il pour autant confondre présence de l'image et orthodoxie de son utilisation, à la manière naïve de ce missionnaire? Comme les témoignages de voyageurs ne cessent de l'attester dès le siècle précédent, les vodouisants se servent abondamment de ces images de piété et contribuent ainsi à leur maintien et à leur diffusion. Métraux conclut d'ailleurs, au lendemain de la Seconde Guerre mondiale, que l'Église, au lieu de pourchasser le vodou, aurait dû porter à son crédit d'avoir assuré la survivance du christianisme dans les milieux populaires (Métraux 1958: 46).

Ainsi, la transmission de l'image chrétienne ne s'opère pas seulement par le canal officiel de l'Église et en milieu urbain, mais aussi par le biais des lieux de culte vodou et de leurs fidèles jusqu'au fin fond des campagnes, au point sans doute d'avoir favorisé quelques peintures qu'Aubin décrit dans un cas et photographie dans l'autre (Aubin 1910: 58 et pl. XXI). En 1884, le Britannique Spenser Buckingham St John note dans son ouvrage sur Haïti, connu pour la vision très négative qu'il donne du pays, la présence de ces images dans les ounfò: «Des gravures prises dans l'Illustrated London News étaient accrochées au mur, des images de la Vierge Marie et de divers saints. Je dois préciser avoir trouvé de telles images ${ }^{\mathbf{1 2}}$ dans chaque ounfò où je suis entré. » (St John 1884: 196) On retrouve ces impressions en noir et blanc et ces chromos sur les lieux que visite Aubin, deux décennies plus tard, dans différents ounfò de la plaine du Cul-de-Sac (Aubin 1910: 61) et dans l'enquête de terrain menée dans la vallée de Mirebalais au cours des années 1930 par Melville Herskovits. Ce dernier signale l'omniprésence des images de saints dans les temples vodou (Herskovits 1971 [1937]: 158, 161), tout particulièrement la Mater Dolorosa pour Erzulie ${ }^{\mathbf{1 3}}$, Notre-Dame de Bon Secours, saint Jacques et saint Antoine. Dans l'univers mental de certains peintres «naïfs » du Centre d'art, qu'elles aient eu leur place n'a rien d'étonnant. L'oungan ${ }^{\mathbf{1 4}}$ Hippolyte, par la fréquentation de ces reproductions bon marché des saints catholiques qu'il affectionnait (Rodman 1988: 57), confirme ce qu'un paysan de Marbial confiait à Métraux: «Pour servir les $10 a^{\mathbf{1 5}}$, il faut être catholique. 》 (Métraux 1958: 287)
11. Celle qui est décrite doit se situer entre les années 1930 et 19451946. Merci à Gusti Gaillard-Pourchet, de l'université d'État d'Haïti, et à sœur Nicole Gaillard, de la congrégation des salésiennes (Port-auPrince), de nous avoir permis de dater ces souvenirs, qui s'étalent en gros de 1915 à 1946 .

12. Traduction de la rédaction de Gradhiva. Celle de 1886 (Haïti ou la République noire, Paris, Plon), de J. West, a choisi de rendre pictures par "tableaux", alors que le contexte semble imposer "images", et of various saints par "objets de sainteté ", ce qui est une interprétation trop large de l'anglais.

13. Erzulie (ou Ezili, en créole) : divinité du culte vaudou, dont la personnalité change suivant le rite observé. L'Erzulie rada, Erzulie Fréda Dahomey, est identifiée à la Vierge dont elle porte les couleurs, le blanc et le bleu.

14. Oungan: prêtre vodou.

15. Loa ou /wa: divinité vodou. 


\section{L'iconographie chrétienne dans la peinture naïve}

La peinture à thèmes chrétiens qui se développe avec le Centre d'art, par sa nouveauté, n'échappe pas plus aux interrogations de fond que toute l'expression plastique qui s'en recommande: représente-t-elle un changement radical par son style, par le choix des sujets, par leur traitement, ou par les trois à la fois? La stupeur qui, sur place, a accompagné la réception des fresques de la Sainte-Trinité (fig. 1) et de la chapelle Sainte-Thérèse de Pétionville, exécutées à peu près au même moment (Drot et Alexis rapportent qu'à Sainte-Thérèse, l'archevêque français fit passer les murs à la chaux; Drot et Alexis 1988: 74, ill.), cette stupeur, si elle est très révélatrice de l'abîme séparant alors la hiérarchie catholique et épiscopalienne, l'élite bourgeoise, une bonne partie des fidèles et les nouveaux peintres, a sans doute contribué à entretenir une extrême confusion sur la signification des œuvres. Quelque quarante ans plus tard, Rodman (1988: 103-117) montre dans des pages souvent savoureuses mais parfois amères qu'il n'a toujours pas oublié (digéré serait plus exact) l'affaire de la Sainte-Trinité, qu'il revit entre autres par le silence du catalogue du Brooklyn Museum sur les fresques qu'il a contribué à voir naître.

Sur la question de la rupture stylistique, il n'est pas inutile de rappeler que, si la référence au Centre d'art est inévitable car celui-ci a incontestablement marqué une césure dans l'art haïtien, certains peintres naïfs ont commencé à s'exprimer bien avant son ouverture et que celle-ci n'a pas impliqué de véritable changement dans leur manière. L'Ascension du Christ d'Obin, datée de 1935 , témoigne bien qu'à cette date son style était déjà largement constitué. Cependant, sur la révolution qu'a constitué le recours à ce type de peinture dans une église au lieu de celle des peintres académiques de la cathédrale catholique voisine (ibid.: 103) ne subsiste aucun doute. Pour autant, croire que les artistes choisis pour la Sainte-Trinité ont spontanément souhaité rejeter le style académique relèverait d'une pieuse illusion. Rodman lui-même ne la partageait manifestement pas puisque, à son équipe (composée de catholiques, seul Obin était protestant), il n'hésita pas à donner la consigne d'oublier les chromos de l'Église romaine (ibid: 107). Prudente précaution? On peut le penser à la vue du Jugement de Salomon d'Obin, tableau exécuté en 1943, que Rodman a reproduit sans le commenter (ibid. : 38): le style est trop différent de celui habituel au peintre qui, par des couleurs pâles, grises ou rabattues de noir, paraît ici puiser son inspiration dans une image de l'Ancien Testament ou une vignette historique en sépia. Quant aux anges de Gabriel Lévêque, qui font tomber sur les fresques du chœur de la cathédrale épiscopalienne une pluie de roses, ils ne paraissent pas avoir coupé tout lien avec l'iconographie de sainte Thérèse, une des figures très populaires de la Fête-Dieu durant ces mêmes années (Mayard s.d. [1967]: 145).

D'une tout autre importance est l'haïtianisation voulue par Rodman, du moins selon la version qu'il nous donne, et saluée par monseigneur Voegeli, le dignitaire épiscopalien qui a donné son aval aux travaux (à la différence de son homologue catholique, consulté au sujet de sa propre cathédrale). Ainsi la Crucifixion d'Obin est-elle plantée dans une rue du Cap et l'Ascension de Bazile se situe dans un bourg, l'enfilade des petites maisons urbaines ou des cases bien visible, avec des mornes à l'arrière-plan. 


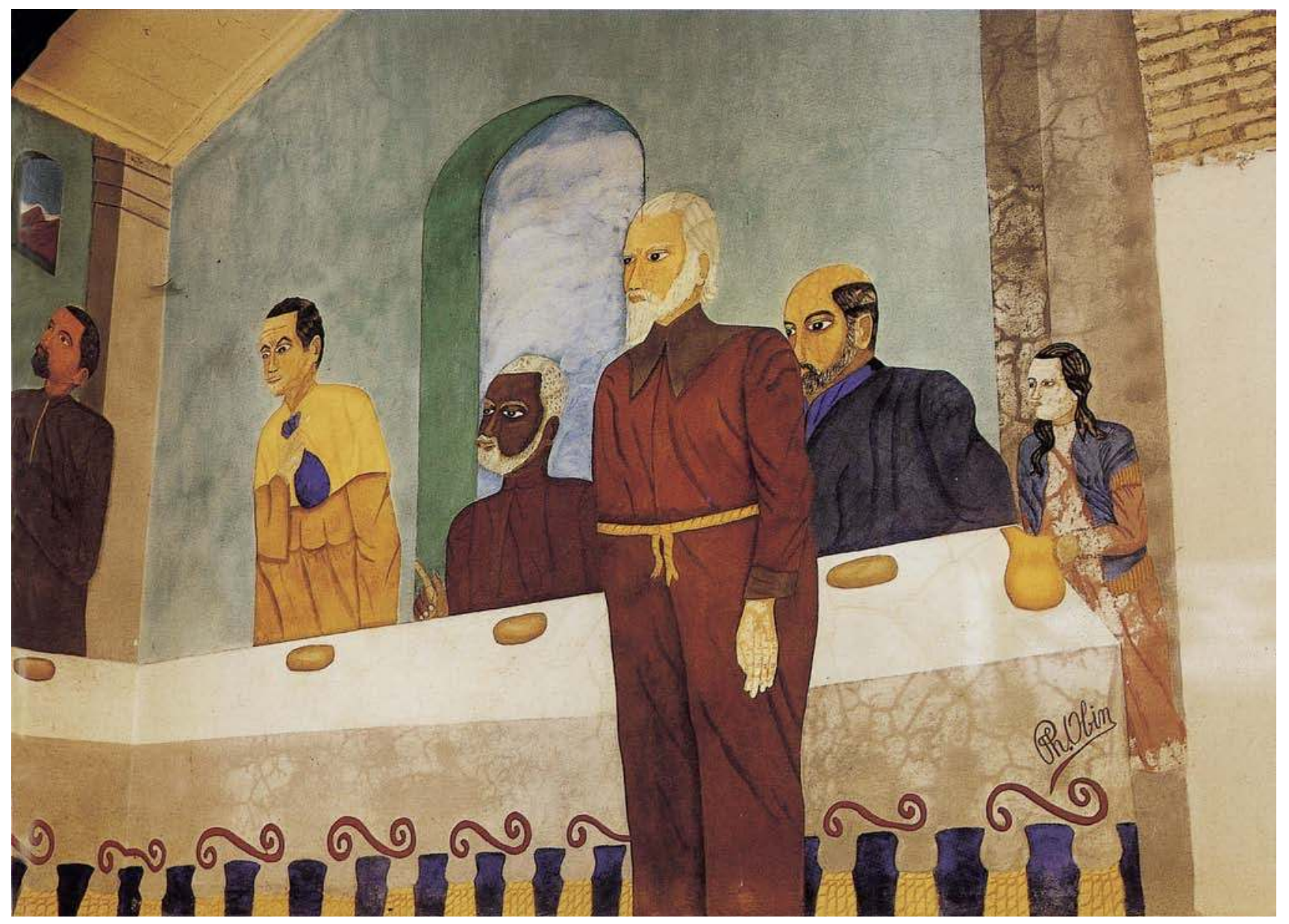

fig. 4

Philomé Obin, La Dernière

Cène, in Jean-Marie Drot,

Voyage au pays des nailfs, 1986, Hatier, p. 168. D.R. 
16. Apparemment, tous étaient rédigés en français, ce qui dénote un certain niveau social.

17. «Sans Jésus, rien n'est bon."

\section{page ci-contre}

fig. 5

Imagerie chrétienne décorant un tap-tap, Port-au-Prince, s.d.

(C) Cultura Travel/Philip

Lee Harvey/Getty images.
L'élément le plus frappant demeure la foule, paysannes coiffées du foulard à deux pointes qui voient s'envoler le Christ de l'Ascension, société plus citadine de la Crucifixion où les femmes arborent beaux vêtements et chapeaux élégants. Cette insertion de scènes religieuses dans la vie quotidienne reste un des choix marquants des peintres qui ont travaillé aux fresques, que ce soient encore les Chemins de croix de Bigaud ou les Apparitions de la Vierge de Bazile. Sans doute est-ce là une innovation d'importance, mais la représentation de personnages sacrés qui reflètent leur appartenance à la société locale par le fait d'être noirs (un des apôtres de la Cène; fig. 4) ou mulâtres (le Christ de la Crucifixion et de l'Ascension), même si leurs traits restent parfois européens, l'est tout autant. Transgression du code en vigueur, sans doute, à laquelle Obin répugne; pourtant, ce n'est pas la première fois qu'un Christ est figuré «de couleur» à Haïti. Seul l'oubli dans la mémoire collective des toiles commandées par Christophe et Soulouque, de la Vierge noire présente sur une des toiles de la cathédrale catholique de Port-au-Prince vers 1860 et du Sauveur noir signalé par St John, et peutêtre plus tardif (Hoffmann 1981: 55), peut laisser croire le contraire dans un contexte que les remises en question de l'indigénisme rendent plus complexe et la reprise en main de l'Église catholique post-concordataire sûrement bien plus rigide.

Cadre fonctionnel par excellence, si l'église est le meilleur support de la peinture chrétienne, elle n'en est pas le lieu unique. Ni même, en ce qui concerne l'art naïf d'inspiration chrétienne, le lieu d'impulsion majeur: la Sainte-Trinité n'a pas fonctionné comme référence normative et n'a pas suscité de véritable émulation puisque au total, même en comptant le triptyque de Léogâne, exécuté entre 1957 et 1962, il ne s'agit que d'un tout petit nombre d'exemples. C'est ailleurs que le dynamisme de cette peinture doit être recherché, à la fois dans le décor des tap-tap (fig. 5) et dans la peinture destinée à une clientèle de collectionneurs.

Les tableaux votifs qui décorent les tap-tap, remerciements, demande d'une grâce, d'une protection, proclamation de l'attachement à telle ou telle figure divine (chrétienne ou vodou), sont à l'origine d'un art populaire authentique qui offre une incontestable plongée dans l'imaginaire religieux haïtien, celui des clients comme des peintres carrossiers chargés de la commande. Reconstituer la genèse historique de ce mode d'expression au xIX $x^{e}$ siècle, ou de ce qui a pu lui ressembler, serait évidemment riche d'enseignements, mais les traces sont minces et guère probantes. Aubin parle bien des ex-voto qu'il a vus à la chapelle de Notre-Dame des Ermites (Aubin 1910: 174), haut lieu de pèlerinage, mais les différences sont manifestes: alors que pour les tap-tap le court message écrit ne vient qu'en appui de l'image, dans le sanctuaire celle-ci fait complètement défaut, avec un texte qui ne renvoie qu'à lui-même ${ }^{16}$. Ce qu'expriment les messages des tap-tap est pourtant d'un grand intérêt, surtout par comparaison avec les thèmes choisis par la peinture de galerie. Les invocations au Christ, très nombreuses (Di tout à Jésus, Christ vivant, Le Bon Pasteur, San Jésu anyin pa bon ${ }^{\mathbf{1 7}}$, Jésus Roi des Rois, Le Bon Berger, Thank you Jésus, Agnus Dei, entre autres), mais aussi à la Vierge (Immaculée, N.-D. Altagrâce, Méci Vierge Miracle, Vierge Mirak, St Marie Mère de Dieu, N.D. du Mont Carmel, N.D. de la Sainte-Croix, Notre Dame du Rosaire...; Paquin 1987, orthographe d'origine), laissent 


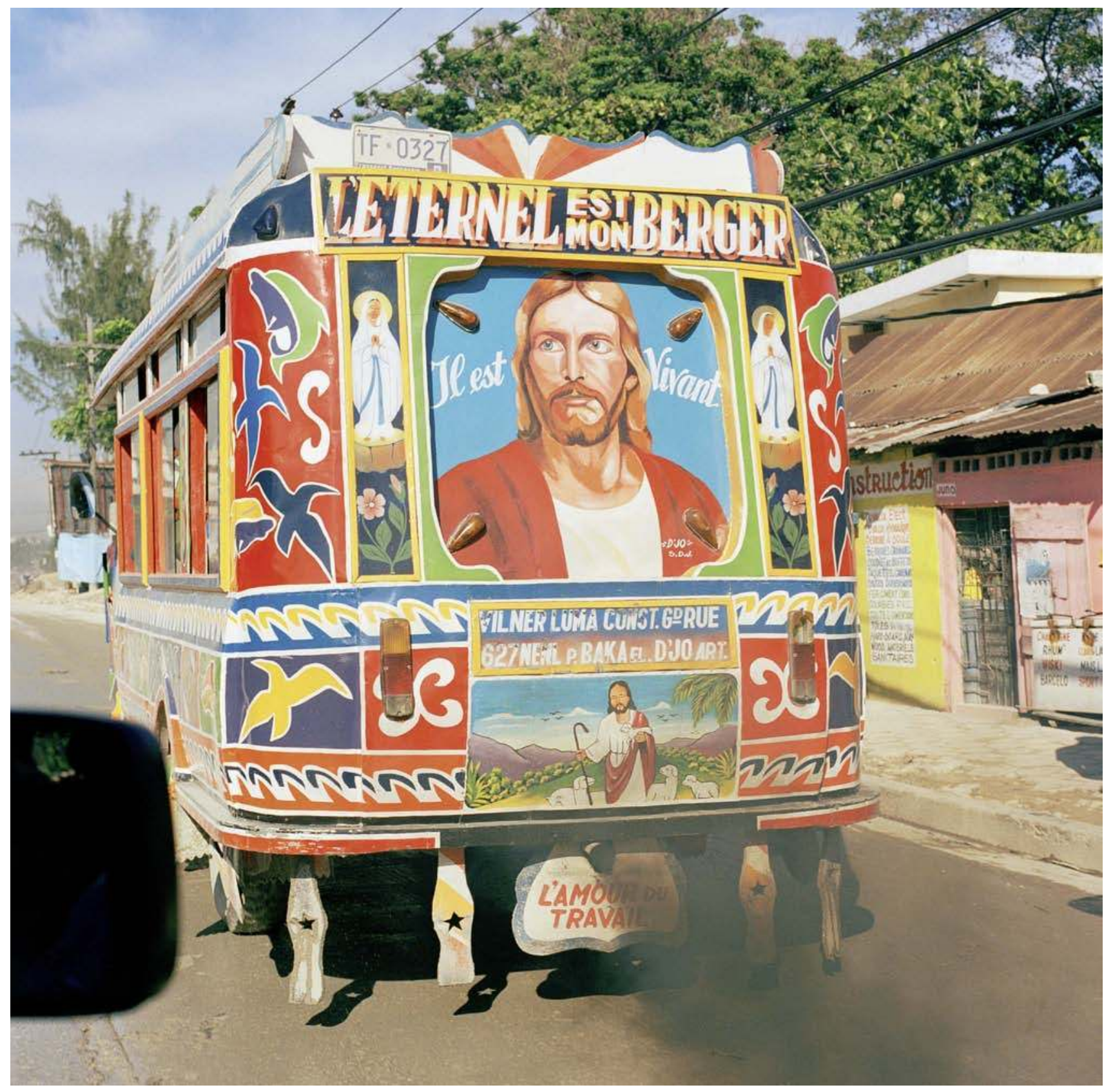




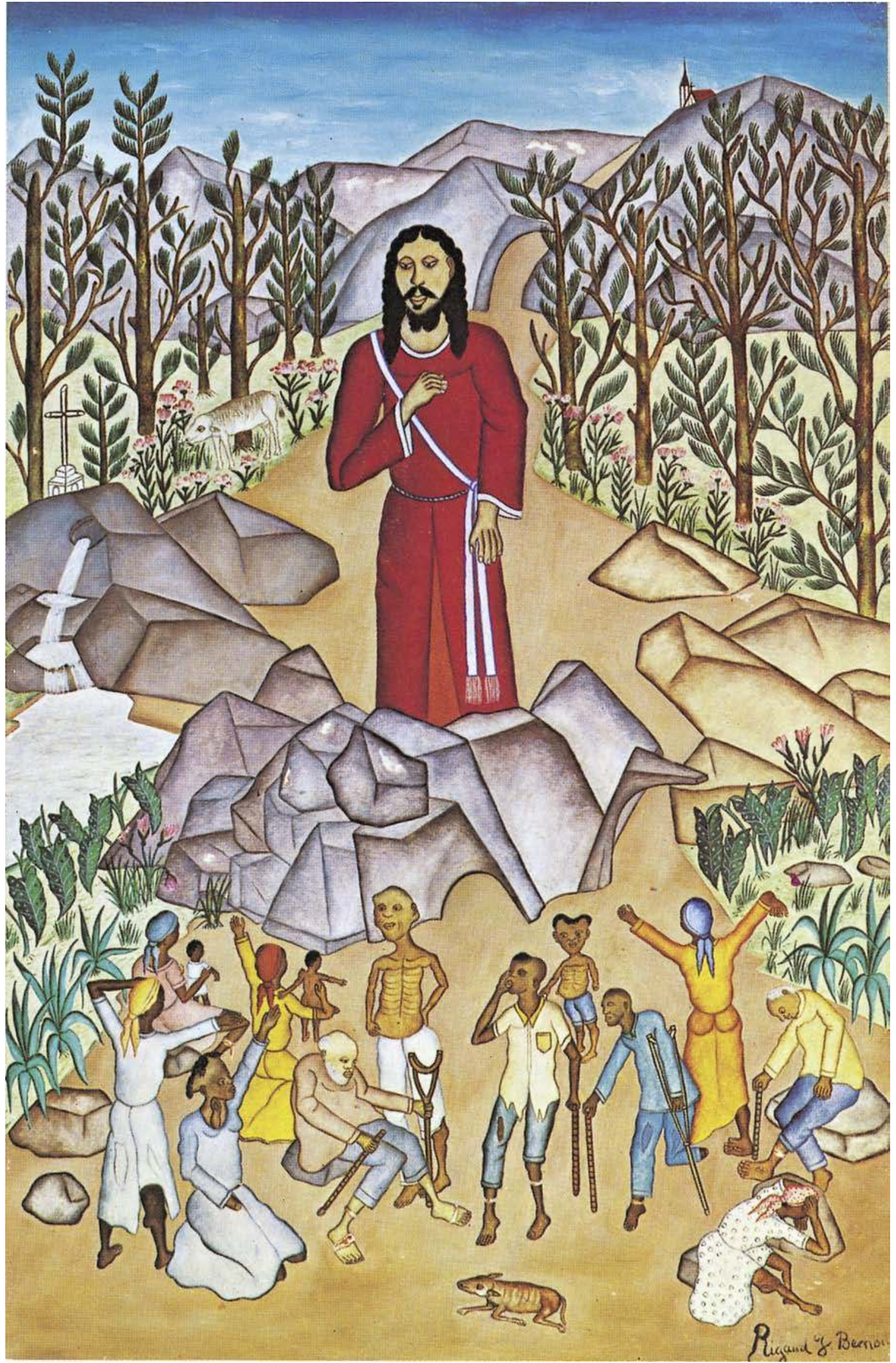


une place importante aux nombreux saints, protecteurs ou thaumaturges. Les références à l'Ancien Testament, très peu courantes dans les autres catégories de peintures (le paradis terrestre excepté), sont ici bien présentes, indiquant peut-être la confession protestante du client: Scapulaire de Salomon, L'Ecclésiaste, La Foi de Job, Les Fils de Jacob, Israël, Yahvé...

Quant aux tableaux sur toile ou carton dur destinés aux réseaux marchands, libérés de toute contrainte de commande, ils font preuve d'une évidente variété dans le choix des sujets même si certains paraissent manifestement plus attractifs que d'autres. Première remarque: tout comme au XIX ${ }^{e}$ siècle, le Nouveau Testament semble beaucoup plus exploité que l'Ancien. La peinture d'église a choisi, pour la Sainte-Trinité, la narration de la vie du Christ et l'annonce de sa venue avec l'Annonciation (Adam Léontis), la Visitation (Fernand Pierre), la Nativité (Rigaud Benoit), la Fuite en Égypte (Toussaint Auguste), le Baptême du Christ (Castera Bazile), l'Expulsion du Temple (du même), la Tentation du Christ (Préfète Duffaut), la Cène (Philomé Obin), la Crucifixion (du même), l'Ascension (Castera Bazile) [Rodman 1988; Drot et Alexis 1988], et les œuvres «libres» ne sont pas en reste. La représentation de la Passion, de Jésus devant Ponce Pilate de Seymour Bottex aux Portements de croix peints à plusieurs reprises dans les années 1950 sur de petits formats par Bigaud (Stebich 1978: 63, vers 1954, ill.) ou à la mise en croix - Obin, Hyppolite (La Dauration l'Amour, vers 1946-1948; Rodman 1988: 34, ill.), Bazile (Crucifixion, 1947; Autoportrait au crucifix, 1950, Port-au-Prince, musée d'Art haïtien; id. : 64 et 54, ill.), Jasmin Joseph (Agnus Dei, vers 1960; id.: 65, ill.), Jacques-Enguerrand Gourgue, Murat Brière, entre autres. La Nativité a également été source d'inspiration pour un certain nombre d'artistes ${ }^{\mathbf{1 8}}$, mais si la Vierge est présente, les Adorations de Bazile (Vierge noire, 1946) ou les Apparitions, du même, ont remplacé les Assomptions des siècles précédents. La représentation de Marie en tant que figure unique du tableau (Castera Bazile, Triomphe, 1947, encore se tient-elle à la droite du Christ adulte; Rodman 1988, 65, ill.), pourtant courante sur les tap-tap, reste rare.

Les miracles et les paraboles du Christ sont très peu sollicités, sauf dans les églises de la Sainte-Trinité (Wilson Bigaud, Les Noces de Cana) et de Léogâne (du même, Sermon sur la montagne et Laissez venir à moi les petits enfants du retable peint en 1962, in Stebich 1978: 61, ill.); une petite huile sur carton, de Benoit, met en scène Jésus guérissant les malades (ibid. : 57, ill. fig. 6). Les théophanies du Nouveau Testament ou de l'Ancien sont absentes; absentes aussi les représentations mystiques du Christ, si prisées dans les images de dévotion françaises du XIX siècle (Bon Pasteur, Ecce Homo), alors qu'on les retrouve sur les tap-tap. Font défaut également les représentations emblématiques du Sacré-Cœur de Jésus, à quelques contre-exemples près (Castera Bazile, Triomphe, déjà cité), ou du mystère de l'eucharistie, très courantes elles aussi dans l'image pieuse française du $X I X^{e}$ siècle. L'enfer ne semble figurer que dans le triptyque de Léogâne, sans doute une des œuvres les plus achevées de la peinture haïtienne d'inspiration chrétienne. L'inspiration eschatologique, d'ailleurs, reste très discrète, même en tenant compte de l'Apocalypse de Joseph (1974; ibid.: 69, ill.). Enfin, la figuration des saints est peu fréquente. À ce titre, le Saint François portant l'Enfant Jésus d'Hyppolite, daté de 1946-1948 (ibid.: 74 et 147),

18. Castera Bazile, vers 1946, où elle joue un rôle secondaire par rapport à l'Annonciation du premier plan, et une autre de 1948, Rigaud Benoit, Sénèque Obin, 1959, Philomé Obin, vers 1960 (illustrations dans Rodman 1988: 64, 80, 97 et 100), Gérard Paul, vers $1980 \ldots$

page ci-contre

fig. 6

Rigaud Benoit, Jésus guérissant les malades, in Cosentino, Donald J. (éd.), Sacred Arts of Haitian Vodou. Los Angeles, 1998 [1995], UCLA Fowler Museum of Cultural History, p.57. D.R. 
19. "Saint Jacques assume la charge! ", selon le savant commentaire de Rachel Beauvoir-Dominique, qui a aimablement assuré la traduction et que nous remercions. La phrase est à double sens: "porte la charge [pour nous] " et «mène la charge [contre eux]". constitue une notable exception, plus d'ailleurs que celle de saint Jacques à cheval, alors même que les décors de tap-tap et les peintures murales de certains ounfò (Hurbon 1983: 73, 75 et 77) montrent la remarquable vitalité de ce type de représentation.

Ce n'est pas un hasard. Dans plus d'un cas, le recours au vodou apparaît, sinon comme un passage obligé, du moins comme une indispensable clé de lecture des œuvres qui mettent en scène le symbolisme chrétien. Mettons à part les incertitudes théologiques, comme dans cette bizarre Ascension d'Obin, déjà mentionnée (le Christ sort de son tombeau dans un espace nu dont il est l'unique occupant, alors que l'épisode se situe normalement quarante jours après Pâques, sans les apôtres, spectateurs qu'il bénit dans l'évangile de saint Luc avant d'être emporté au ciel), ou ce Saint François... d'Hippolyte qui ferait plutôt penser, comme le remarquait Ute Stebich (1978: 74 et 147), à saint Antoine ou à saint Joseph, traditionnels porteurs de l'Enfant. En revanche, sur un plan beaucoup plus général, la faible occurrence de la représentation de la Vierge et des saints aussi bien dans la peinture officielle (d'église) que dans celle des réseaux marchands ne peut se passer d'une explication où apparaît le doublon vodou. Comme Marie s'efface devant les Erzulie des vodouisants, le saint catholique est avalé par sa fonction de Iwa, plus aisément exprimée par l'imagerie populaire des drapeaux vodou et des décors de tap-tap ou d'ounfò qui laissent libre cours à l'ambiguïté de la nature et des pouvoirs de la divinité: ainsi du St-Jacques poté pou yo ${ }^{19}$ affiché par un autobus, qui s'adresse derrière saint Jacques à Ogoun, le Iwa guerrier. Quant à l'Adoration des mages, thème très à l'honneur dans les îles au moins jusqu'à la fin du XVII siècle puisqu'il était présent à Saint-Christophe dans la procession du jour des Rois destinée aux esclaves (Chatillon 1984: 120), elle a complètement basculé du côté des croyances vodou. Celles-ci sont rarement à écarter comme élément de compréhension, même quand le thème est entièrement chrétien, et surtout quand le peintre est un adepte. Sans tomber dans une systématisation excessive, on peut admettre, si l'on suit l'interprétation d'André Pierre reprise avec prudence par Stebich (1978: 73, ill.), que la Crucifixion exécutée par Hippolyte (La Dauration l'amour) met en scène un Christ Baron La Croix entouré d'ounsi, initiées qui servent dans les ounfò. De même, chez Benoit, Jésus guérissant les malades est peut-être, par la robe rouge du Christ, dédié à Ogoun (ibid.: 86, ill. des deux tableaux). Demeure l'énigme du grand écart qu'effectuent les titres de certains tableaux, donnés après coup, on le suppose, en dehors de l'artiste et qui influent fâcheusement sur le commentaire qu'on peut tirer de l'œuvre: le même Jugement dernier au-dessus de Jacmel de Duffaut, reproduit par Drot, devient ainsi chez Stebich Tentation du Christ et pour Rodman, qui le relie aux esquisses des peintures murales de la Sainte-Trinité, La Reine Titane (Drot 1974: 45, ill.; Stebich 1978: 86, ill. ; Rodman 1988: 108, ill.)...

Aucun de ces thèmes n'occupe autant de place que celui du paradis terrestre. Source d'inspiration exceptionnelle pour certains peintres phares du Centre d'art comme Bigaud, d'autres artistes lui ont voué une dévotion toute particulière, pour certains presque exclusive: Salnave PhilippeAuguste, Alexandre Grégoire, Jasmin Joseph, André Normil, mais aussi Jocelyn Agenor, Daniel Orélus... Cela mérite que nous nous y arrêtions. Car, 
si le récit du péché originel et son support iconographique ont été utilisés dans la catéchèse missionnaire de la fin du xvı ${ }^{e}$ siècle, comme le montre la correspondance du père de La Mousse (Bianchi 1984: 186), il ne s'agit pas d'une image courante de dévotion au XIX siècle, du moins en France. On les retrouve cependant à la même époque dans les estampes populaires italiennes où la création du monde, avec Adam et Ève, le serpent et le pommier, et Dieu le Père entouré d'animaux, est une histoire particulièrement prisée $^{20}$ (Toschi 1965 [1963]: 37). Que, par le biais des prêtres étrangers, le passage de ces images à Haïti durant la période préconcordataire ait été possible n'empêche pas que reste posée la question de fond: pourquoi ce sujet-là, précisément?

D'abord parce qu'il se nourrit très aisément, dans ses exégèses, de ce qui a longtemps fait florès pour justifier la grande aventure de l'art haïtien après 1944: le recours explicatif et systématique à l'extase comme source d'inspiration, dans lequel tant de critiques d'art, en particulier étrangers, ont communié. Difficile de s'empêcher de penser, dans ces conditions, qu'une demande accrue, séduite par ce qui peut apparaitre comme un gage d'authenticité, n'ait pas entraîné l'offre dans son sillage. Deuxième raison, quelque peu paradoxale par rapport à ce qui précède: très vraisemblablement parce que ces représentations de l'éden ont fini par sortir du domaine religieux, confirmant cette mise en garde que lançait Michel Albaric à propos de la production massive d'images pieuses dans la France de la première moitié du xx siècle: «Sous prétexte que l'artiste est un maître, que le sujet est religieux, l'œuvre est-elle religieuse? » (Rosenbaum-Dondaine 1984: 177) Entre le puissant Paradis terrestre d'un Bigaud (1952; fig. 2), contemporain des fresques de la Sainte-Trinité, ou les Adam et Ève de Joseph, certains poignants (Adam et Ève après la faute, vers 1960) - visibles au musée d'Art du collège Saint-Pierre de Port-au-Prince -, et le rendu charmant mais simplement décoratif des Jardins d'éden de Philippe-Auguste (1972; Drot 1974 : 39; fig. 7) ou encore les visions oniriques que Roland Blain exécute dans les années 1980 (Ėve aux crocodiles; Rodman 1982: 41, ill.), les ressemblances ne sont que de surface. Elles ne masquent pas la perte de sens du thème et sa dévitalisation ornementaliste. Que ces paysages gorgés d'une végétation exubérante parlent avec nostalgie à l'âme haïtienne d'un pays d'autrefois, mais transmuté, sublimé, est possible (Bégot 1988); mais que l'imaginaire occidental y ait renoué, par ces Ève noires et ces lianes improbables, ces animaux d'ailleurs, même pour Haïti (lions, zèbres, girafes...), avec sa passion pour l'exotisme, est certain. Entre les jungles profanes de certains peintres et les paradis terrestres où Adam et Ève ne sont plus que de simples accessoires, quelle différence, au fond? Ils incarnent de la même façon le rendez-vous entre un produit, cette «production à la chaîne " que dénonce très tôt Lerebours (1989: 189), et un marché, celui du tourisme de masse. Pinti-a dérapé an mim tan ak mouvman touris la 21 (Sèl 1977 : 28).

Malgré tout, il se pourrait que la peinture d'inspiration chrétienne, du moins celle qui s'inscrit dans ce courant des arts dits naïfs qui a tant compté dans la seconde moitié $d u x x^{e}$ siècle, en ait retiré un grand bienfait: le témoignage de sa profonde historicité. Sans doute le constat est-il valable aussi pour les arts du vodou, mais il n'est pas inutile d'y revenir pour l'expression chrétienne tant le rapport à l'histoire paraît avoir été gommé de
20. L'estampe reproduite, napolitaine, date de 1849 .

21. "La peinture a dérapé en même temps que le mouvement touristique." 


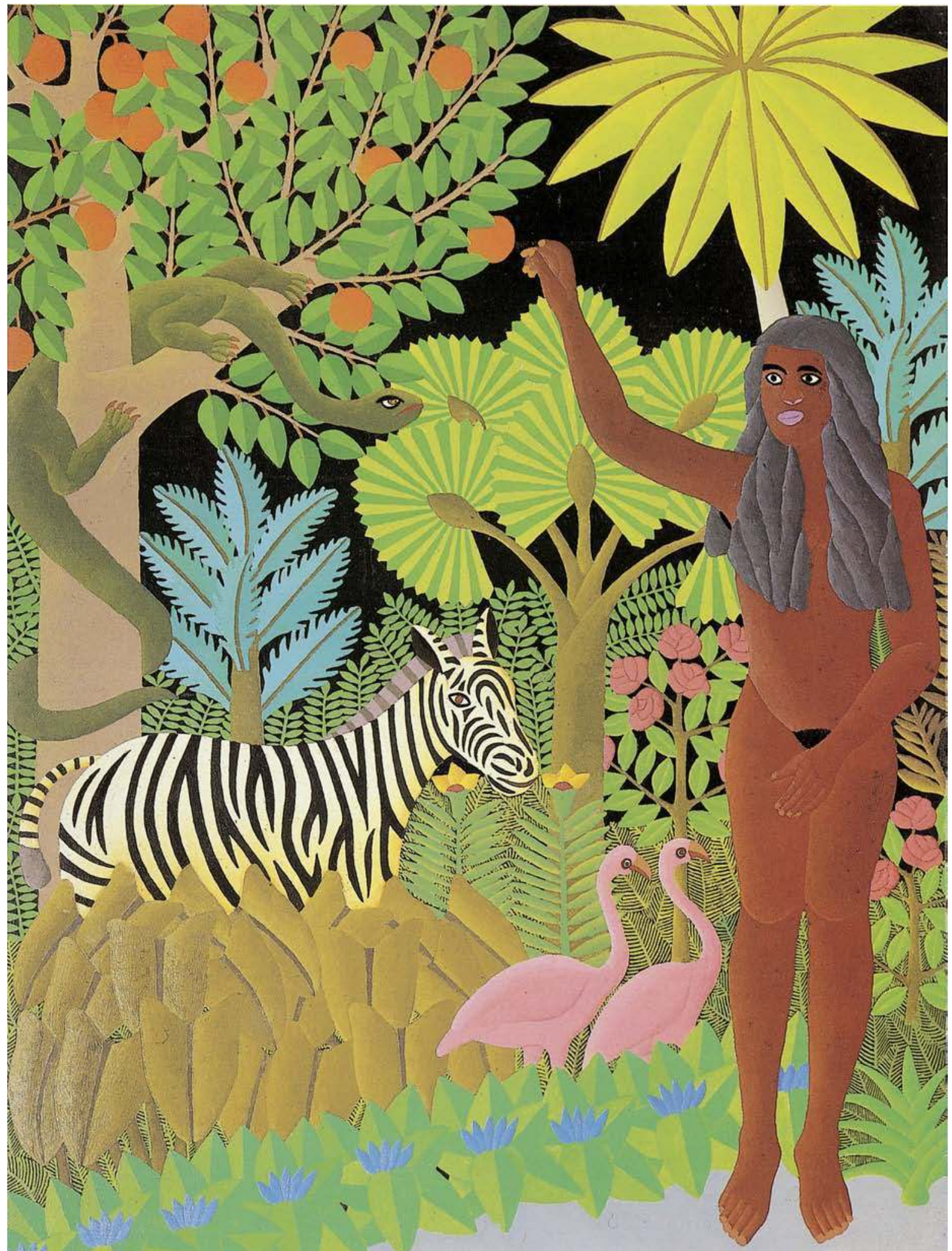


l'analyse des œuvres dans la riche production plastique de cette époque. $\mathrm{Ni}$ les fresques de la Sainte-Trinité ni la vogue des paradis terrestres ne peuvent s'expliquer sans référence au contexte très particulier de leur naissance. Par-delà leur fonction religieuse pour les fresques de la cathédrale épiscopalienne ou leur lien avec le marché de l'art pour les paradis, c'est bien la réaffirmation d'une des caractéristiques premières de cette iconographie qui s'impose: le miroir que ces œuvres représentent pour une société donnée à un moment donné. Ou, si l'on préfère, «l'image comme écho ", pour reprendre le beau titre de Maximilien Laroche...

Université des Antilles et de la Guyane dbegot@gmail.com 
Bibliographie

\section{Aubin, Eugène}

1910 En Haiti : planteurs

d'autrefois, nègres d'aujourd'hui.

Paris, Armand Colin.

\section{Bastien, Lisa}

1954 «Pintura popular de Haiti», Cuadernos Americanos LXXIII (1): $215-232$

\section{Bastien, Rémy}

1966 «Vodoun and politics in Haiti », in Rémy Bastien et Harold Courlander, Religion and Politics in Haiti, Two Essays. Washington, Institute for a Cross-Cultural Research.

\section{Bégot, Danielle}

1988 «Peinture et identité, l'imaginaire du paysage dans la peinture cubaine du XIXe siècle et dans la peinture haïtienne indigéniste ", in Cuba et les Antilles. Bordeaux, Presses Universitaires de Bordeaux: 90-104.

2006 «Moreau de Saint-Méry et les monuments de Saint-Domingue », in Moreau de Saint-Méry ou les ambiguités d'un créole des Lumières, actes du colloque organisé par les archives départementales de la Martinique (2004). Fort-de-France, SAAR: 159-172.

\section{Bianchi, Marie-Pierre}

1984 «Un missionnaire jésuite en Guyane pendant la seconde moitié du xvil siècle: Jean de La Mousse 1650-1699 », mémoire de maîtrise, université Lyon III.

\section{Bonnaud, Léon}

1938 Apostolat en Haiti, journal d'un missionnaire. Priziac, Imprimerie des apprentis orphelins de Saint-Michel.

\section{Cabon, R.P. Adolphe}

1933 Notes sur l'histoire religieuse d'Haiti: de la Révolution au Concordat (1789-1860). Port-au-Prince, collège Saint-Martial.

La peinture naïve haïtienne d'inspiration chrétienne. Par Danielle Bégot

\section{Célius, Carlo Avierl}

2001 «L'avènement de l'art naïf en Haiiti, discours institué et nouvelles approches", thèse, École des hautes études en sciences sociales.

2005 «La création plastique et le tournant ethnologique en Haït», Gradhiva 1 («Haïti et l'anthropologie $»): 71-94$

\section{Chatillon, Marcel}

1984 "L'évangélisation des esclaves au xvII siècle. Lettres du R.P. Mongin ", Bulletin de la Société d'histoire de la Guadeloupe 61-62.

\section{Cliquot, Robert}

s.d. [1840] Cérémonies et fêtes de la réédification de l'église du Cap Haitien en août 1840. Port-au-Prince, impr. J. Courtois, in- $4^{\circ}$

\section{Debien, Gabriel}

1974 Les Esclaves aux Antilles françaises (XVII-XVIII siècles).

Basse-Terre et Fort-de-France,

Société d'histoire de la GuadeloupeSociété d'histoire de la Martinique.

\section{Delisle, Philippe}

2003 Le Catholicisme en Haiti au XI $x^{e}$ siècle. Le rêve d'une Bretagne noire (1860-1915). Paris, Karthala.

2006 Catholicisme, esclavage et acculturation dans la Caraïbe francophone et en Guyane au xixe siècle. Matoury, Ibis Rouge éditions.

\section{Drot, Jean-Marie}

1974 Journal de voyage au pays de la fête et du vodou. Genève, Skira.

\section{Drot, Jean-Marie et Alexis, Gérald}

1988 Haiti: art naif, art vodou, catalogue d'exposition. Paris, Galeries nationales du Grand Palais.

\section{Fouchard, Jean}

1988a [1953] Les Marrons

du syllabaire. Port-au-Prince, H. Deschamps.

1988b [1955] Les Plaisirs de Saint-Domingue. Port-au-Prince, H. Deschamps.

\section{Frostin, Charles}

1979 «Méthodologie missionnaire et sentiment religieux en Amérique française aux XVII' et XVIII siècles: le cas de Saint-Domingue ",

Cahiers d'histoire 24: 19-43.

\section{Gombrich, Ernst}

1978 [1963] Meditations on a Hobby Horse. Oxford, Phaidon Press.

1983 [1972] «L'image visuelle», L'Écologie des images.

Paris, Flammarion.

\section{Herskovits, Melville}

1971 [1937] Life in a Haitian Valley. New York, Doubleday and Company.

\section{Hoffmann, Léon-François}

1981 « Notes pour servir à I'histoire de la peinture haiitienne au xIx siècle", Conjonction, revue franco-haitienne 151 («L'histoire d'Haïti vue par les peintres $")$ : 43-72.

\section{Hurbon, Laënnec}

1972 Dieu dans le vodou haitien. Paris, Payot.

1983 Les Mystères du vodou. Paris, Gallimard.

1987 Comprendre Haiti. Portau-Prince et Paris, H. Deschamps - Karthala.

Le Clézio, Jean-Marie-Gustave

2011 Les musées sont des mondes. Paris, GallimardMusée du Louvre Éditions.

\section{Le Goff, Jacques [dir.]}

1968 Hérésies et sociétés dans $l^{\prime} E$ Europe préindustrielle, $\left.X\right|^{\ominus}-X V I I^{\ominus}$ siècles, colloque de Royaumont.

\section{Lerebours,}

\section{Michel-Philippe}

1981 «Peinture, société et culture haïtiennes », in « Cours international d'été d'Haïti, Patrimoine culturel, document de synthèse ». Port-auPrince, collection CHISS (ronéoté).

1989 Haiti et ses peintres de 1804 à 1980. Souffrances et espoirs d'un peuple. Portau-Prince, Imprimeur II.

\section{Mayard, Yvonne}

s.d. [1967] Autrefois nan pays d'Haiti. Port-au-Prince, Imprimerie centrale.

\section{Métraux, Alfred}

1958 Le Vodou haitien. Paris, Gallimard.

\section{Milscent, Jules Solime}

1820 «Incendie au Port-au-Prince », L'Abeille haytienne 17-21.

\section{Moïse, Claude [dir.]}

2003 Dictionnaire historique de la Révolution haitienne (1789-1804). Montréal, Éditions Images-CIDIHCA (article sur Henri Christophe: Kethly Millet).

\section{Moreau de Saint-Méry, Médéric Louis Élie} 1984 [1796-1797] Description de la partie française de l'isle de Saint-Domingue. Paris, SHOM, 3 vol.

Nadal-Gardère, MarieJosé et Bloncourt, Gérald

1986 La Peinture haiitienne. Paris, Nathan.

\section{Paquin, Lyonel}

1987 Les Tap-tap haitiens, 1000 messages et slogans. Port-au-Prince, Lyonel Paquin.

\section{Rodman, Selden}

1950 « The Christ of the Haitian Primitives ", Harper's Bazaar, décembre: $106-109$ et 175-177.

1982 Artists in Tune with their World. New York, Simon \& Schuster.

1988 Where Art is Joy. New York, Ruggles de Latour.

\section{Rosebaum-Dondaine, Catherine}

1984 L'Image de piété en France, 1814-1914. Paris, musée-galerie de la Seita.

\section{Schoelcher, Victor}

1843 Colonies étrangères et Haiti: résultats de l'émancipation anglaise, t. II. Paris, Pagnerre. 
Sèl [Jounal ayinsyin alétranjé]

1977 «Pinti ayisyin », numéro

\section{Stebich, Ute}

1978 Haitian Art, catalogue

Abrams-The Brooklyn Museum.

St John, Spenser

Buckhingham

1884 Hayti or the Black Republic.

Londres, Smith Elder.

Toschi, Paolo

1965 [1963] L'Imagerie populaire

Deux Mondes.

Warren, Leon E.

1978 Peintures haïtien

Boulogne, Delroisse. page 22 et ci-contre Terrestre, 1952, huile sur Terrestre, 1952, huile sur isorel. Musée d'Art haïtien du collège Saint-Pierre. Don du Centre d'Art. @) Photo Dominique Franck Simon / Photo Pro Studio.

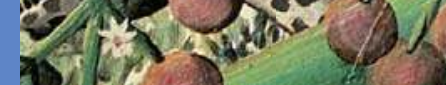
$\int_{1}$

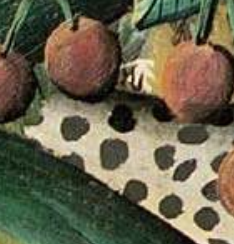
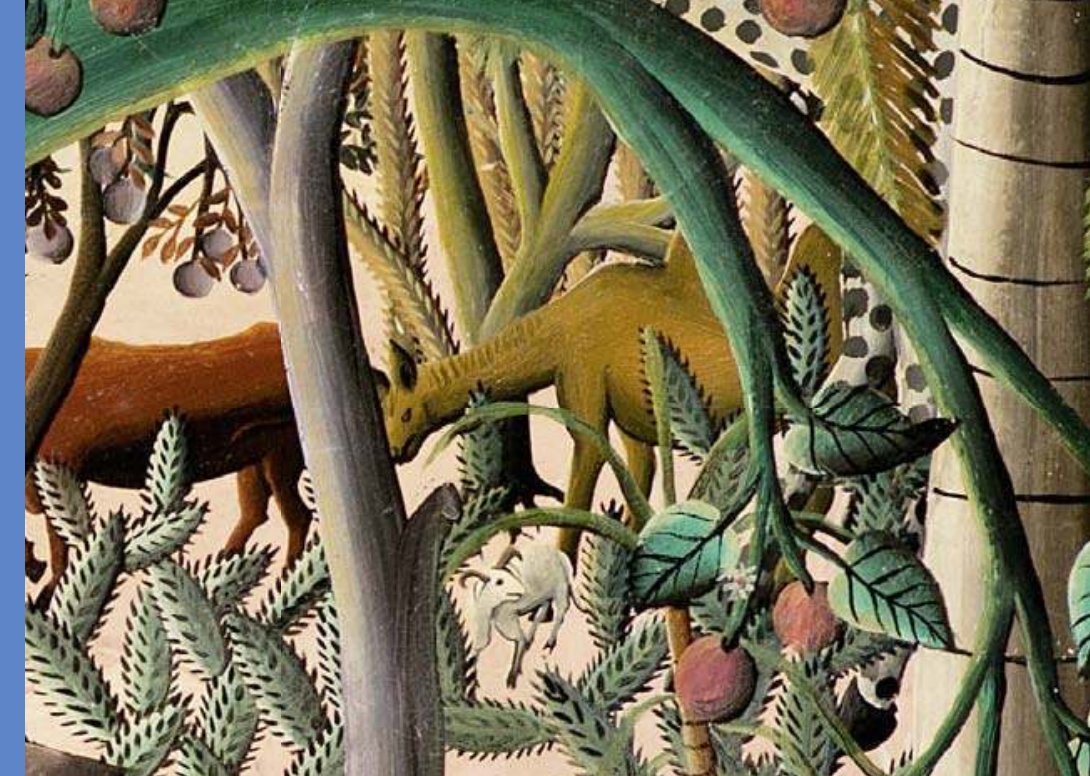
(1)
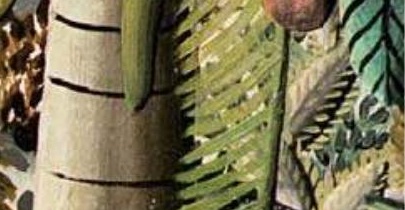

$2 \operatorname{lol}^{2} \frac{\varepsilon}{2}$
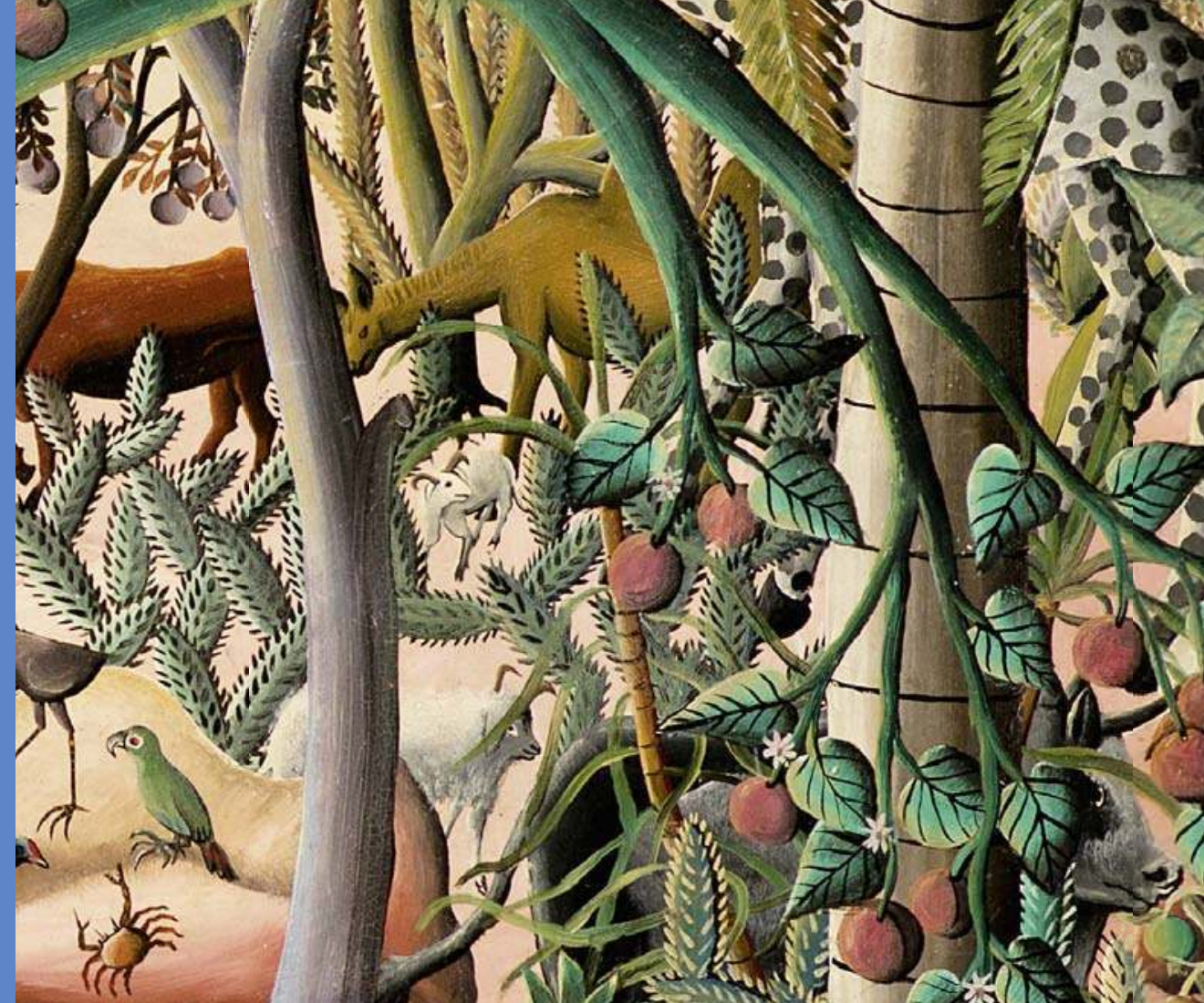
$1 \mathrm{C}^{2} \mathrm{~A}$

(1) को

1.

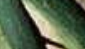

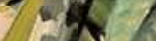
(a) dir
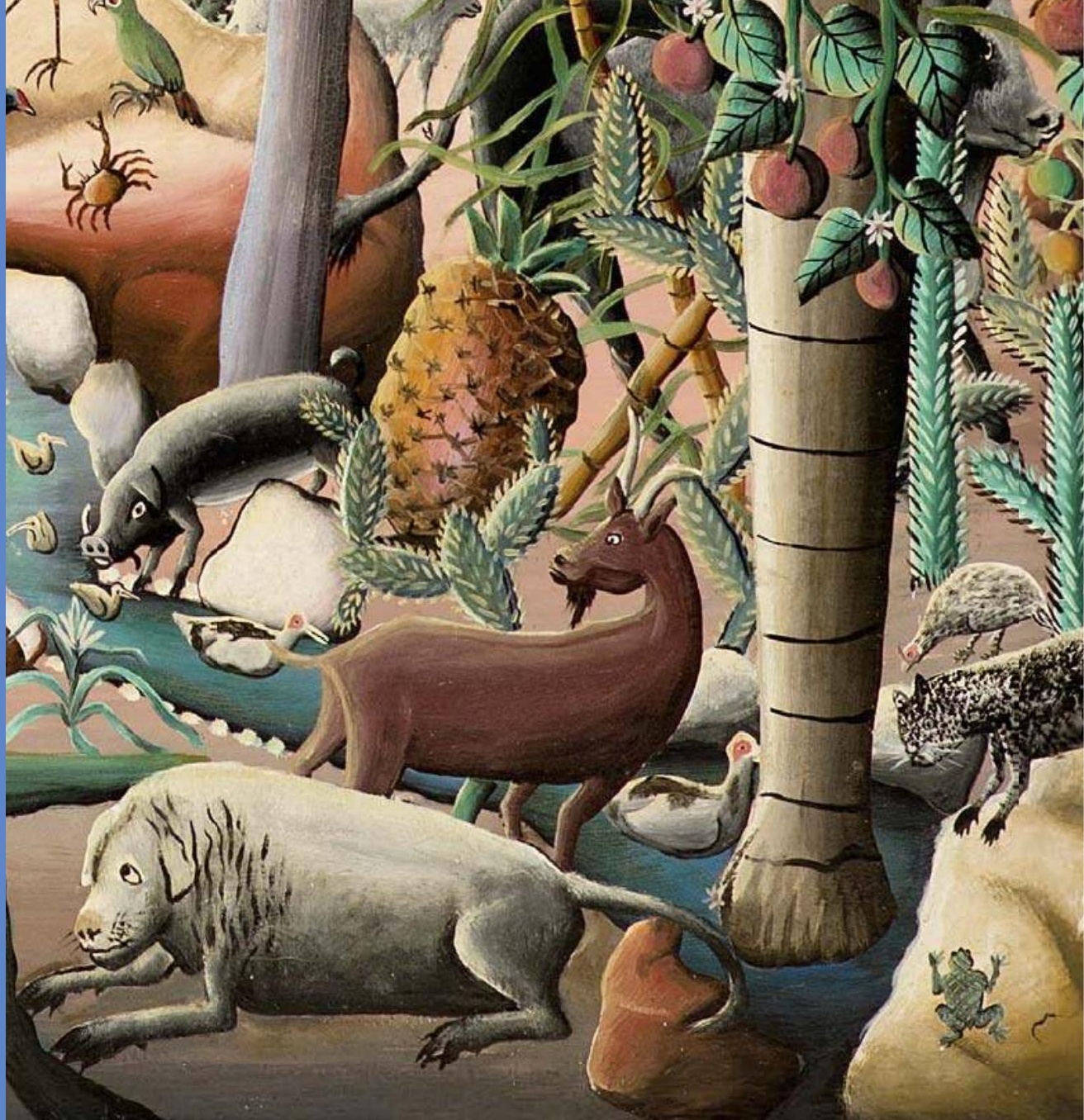